IFN Working Paper No. 1106, 2016

\title{
Does Financial Deregulation Boost Top Incomes? Evidence from the Big Bang
}

Julia Tanndal and Daniel Waldenström 


\title{
Does Financial Deregulation Boost Top Incomes? Evidence from the Big Bang*
}

\author{
Julia Tanndal ${ }^{\dagger}$ and Daniel Waldenström ${ }^{\ddagger}$
}

January 27, 2016

\begin{abstract}
This study estimates the impact of financial deregulation on top income shares. Using the novel econometric method of constructing synthetic control groups, we show that the "Big Bang"-deregulations in the United Kingdom in 1986 and Japan 1997-1999 increased the share of pre-tax incomes going to top earners by over 20 percent in the U.K. and over 10 percent in Japan. The effect is strongest in the top five percentiles in the U.K. whereas it is mainly driven by the lower part of the top decile in Japan. The findings are robust to placebo tests, alternative ways to construct synthetic controls and scrutiny of post-treatment trends. Higher earnings among financial sector employees appear to be an important mechanism behind this result.
\end{abstract}

*We are grateful for comments from Adrian Adermon, Charlotte Bartels, Magne Mogstad, Thomas Philippon, Ariell Reshef and Andreas Peichl. Financial support from the Swedish Research Council is gratefully acknowledged.

${ }^{\dagger}$ Department of Economics, Brown University

${ }_{\ddagger}^{\ddagger}$ Department of Economics, Uppsala University and CEPR, IZA and IFN. Email: daniel.waldenstrom@nek.uu.se 


\section{Introduction}

In the light of the most recent financial crisis, a discussion has re-emerged about who gains and who loses from governmental policy. One specific line of conflict is the very top one percent of income earners versus the other 99 percent. Even when leaving the turbulent setting of a crisis behind, the question of winners and losers from public policy still stands, especially for policies related to the financial sector. The focus of this study is on the distributional consequences of the vast deregulations of financial and stock markets that helped creating global financial centers in London and Tokyo during the 1980s and 1990s.

Even though the relationship between financial market development and top incomes is of great concern, this question has not received much attention in the previous research literature. Studies of finance and inequality have mainly focused on the low end of the distribution (e.g., Demirgüç-Kunt and Levine, 2009; Beck, Demirgüç-Kunt and Levine, 2007; Clarke et al., 2006) or on specific groups of high-income earners in the U.S. (Kaplan and Rauh, 2010; Philippon and Reshef, 2012; Nabar and Jerzmanowski, 2013). Roine, Vlachos and Waldenström (2009) study top income shares and indicators of financial development but focus on broad correlation patterns over very long-run historical periods.

In this study, we intend to estimate how top income shares are influenced by financial deregulation. We do this by focusing on two well-known large-scale financial market reforms, the "Big Bangs" in the U.K. in 1986 (Clemons and Weber, 1990) and Japan in 1997-1999 (Toya and Amyx, 2006). ${ }^{1}$ These Big Bangs incorporated a wide range of reforms that were especially concerned with stock market liberalizations and they were carried out over a quite limited time period. Deregulations did, of course, occur in other countries as well during the 1980s and 1990s, but they were both more gradual and had less of the concentrated and profound impact that is attributed to the Big Bangs.

Several potential channels could explain why financial deregulation drives top income shares. One centers on higher profitability in the financial sector caused by the deregulation, and how the gains are distributed to employees and management of the financial firms in the form of higher remuneration. ${ }^{2}$ Another possible channel works through higher wealth returns as result of more efficient markets and cheaper investment ser-

\footnotetext{
${ }^{1}$ We use data on top income shares from the World Wealth and Income Database, www.wid.world (2016/01/07).

${ }^{2}$ This association is documented by, e.g., Philippon and Reshef (2012, 2013). However, whether this is an efficient outcome, signaling higher productivity of finance workers remains an open question. For example, Böhm, Metzger and Strömberg (2015) are unable to link the finance wage premium to cognitive or non-cognitive skills using military enlistment records from Sweden and conclude that "rents in finance are high, increasing, and largely unexplained".
} 
vices after the deregulation, which primarily benefits top income earners with relatively large share of income from capital.

Identifying causal impacts on top income shares has been a key challenge in previous studies of top incomes. Our strategy to overcome this problem is to use the new synthetic control methodology proposed recently by Abadie, Diamond and Heinmüller (2010). ${ }^{3}$ The idea behind this method is to construct a control group that reflects what would have happened to the income distribution in the treated country, i.e., the U.K. or Japan, in the absence of the financial deregulation. Rather than choosing one or more countries to use as a comparison group (which would be a standard difference-indifference approach), a synthetic control group is created by using a weighted average of countries that are selected based on their similarities with the treated country in terms of the historical evolution of top income shares and of important background characteristics. Compared with other types of comparative case studies, this results in a data-driven approach which provides a better match to the counterfactual trend and also reduces the risk that the results are driven by unobserved shifts in the control group.

The critical assumption of the synthetic control method is that a match in pretreatment trends between a country and a synthetic control group indicates that they would have continued to follow the same trend, in absence of treatment. This nonparametric choice of a counterfactual has benefits when studying top income shares that may be affected by global or regional trends depending on the institutions of the nation studied. However, it is possible that there are no common trends in top income shares between similar countries and, if so, that the assumption is unlikely to hold. We assess this eventuality by varying the controls used to construct the synthetic control group, and we also use placebo tests which reveal if the estimated effects of treated countries are among the most extreme. In addition, we examine the assumption about post-treatment trends in control variables being parallel between treated and control countries.

Our findings indicate that the financial deregulations had a strong and positive effect on top income shares in the U.K. and Japan. The results are largest in the U.K., where top income shares increased by over 20 percent compared to the synthetic control group. In Japan, they increased by about 10 percent as a result of the Big bang. When distinguishing between different groups within the income top, we find that the effect in the U.K. is confined to the very top percentiles of the distribution whereas it in Japan is primarily driven by the groups just below the top percentile. When accounting for these patterns, we find that the most likely explanation relates to the

${ }^{3}$ An early version of the method was used in Abadie and Gardeazabal (2003) 
labor market and higher earnings to people working in the financial sector. While we currently lack detailed cross-country data on the composition of top incomes by income source, evidence in the U.K. and Japan show that top incomes in these countries are primarily made up of wages and that, at least in Japan, the share of wages in total top incomes increased during the years after the Big Bang (Atkinson, 2007; Moriguchi and Saez, 2008; Bell and van Reenen, 2010). Although we have no information about from which sector these wage incomes emanate, this overall pattern goes well together with the findings of previous studies showing a strong correlation between financial market deregulations and wage incomes in the financial sector (e.g., Philippon and Reshef, 2012, 2013; Boustanifar, Grant and Reshef, 2016). In contrast, we find less support for the alternative main channel working through higher wealth returns which disproportionately increase capital incomes among top earners. We document the strongest deregulation effects among groups, just below the absolute top of the income distribution where typically the super-rich capital owners reside. Furthermore, when we include realized capital gains in top incomes, which is expected to boost deregulation effects if higher wealth returns is the main channel, effects are weaker or absent, which reinforces the labor-market related explanation.

The study complements the research on the evolution of top incomes. Over the past decades top income shares have risen dramatically in many OECD countries. In AngloSaxon countries the share of all incomes going to the top percentile has roughly doubled between 1980 and 2010 while the increase has been less dramatic in other countries (Atkinson and Piketty, 2007, 2010). Several explanations have been proposed, but it is fair to say that consensus has not been reached. Some studies point at marketdriven factors such as trade globalization and technological change (e.g., Gabaix and Landier, 2008) while others emphasize the role of redistributive political institutions (Piketty and Saez, 2007; Roine et al., 2009; Piketty, Saez and Stantcheva, 2014) or social norms concerning top earnings, not least involving the top-earning individuals who are in position to influence their own wages (e.g., Saez and Veall, 2005; Bebchuk, Fried and Walker, 2002). A recent strand of this literature emphasizes the role of structures and, in particular, the importance of within-firm developments (Song et al., 2015). While the role of financial markets has been examined previously (e.g., Roine et al., 2009), our emphasis on estimating a causal relationship between financial regulatory change and top income shares appears to be a specific contribution to the literature.

The rest of the paper is organized as follows. Section 2 describes the institutional background of the Big Bang deregulations in the U.K. and Japan, and section 3 discusses the potential mechanisms that could account for the link between financial deregulation and top incomes. Section 4 presents the econometric methodology and the data 
used. The main results are presented in section 5 and robustness tests are presented in section 6 . Finally, section 7 concludes.

\section{Financial deregulations and the Big Bangs}

Financial markets have been regulated during most of the twentieth century. After the great depression and the World Wars, most developed economies deemed it fit to control capital flows, financial services and interest rates (Rajan and Zingales, 2003). The deregulation of this industry began during the 1970s and 1980s, with gradual releases of restrictions of international capital transactions or interest rates (Williamson and Mahar, 1998).

Many previous studies of financial deregulations have looked at the deregulations in the United States as a case study. ${ }^{4}$ The long time span, together with the state variation (e.g., top income earner mobility across U.S. states) makes the U.S. deregulations unsuitable for evaluating the distributional effects of financial deregulation.

Overall the big bangs distinguish themselves not only due to the level or speed of deregulations, but also because of the political ambition that these bangs would move the focus of world finance to their metropolis. The ambitions for the London and Tokyo stock exchanges clearly show that the intentions of these policies were not just to catch up with the international standard of financial markets, they were trying to stay on top.

\subsection{The U.K. Big Bang in 1986}

The "Big Bang" in the U.K. was entirely directed towards the stock market with a clear aim to revitalize the City of London as the world's leading financial center. The reforms were implemented in October 1986, and they allowed foreign and non-specialized firms to enter the stock market and for multiple trading functions within the same company (Bellringer and Michie, 2014). ${ }^{5}$ The fixed commission rates were abolished, and the whole interaction between traders was restructured. Now, a single firm could both

\footnotetext{
${ }^{4}$ The financial market deregulations in the US have been used as a good natural experiment for studying various effects of deregulations, where the most popular deregulation to study is the opening for intrastate banking, which was implemented by different states at different times (see for example Hubbard and Palia, 1995; Beck, Levine and Levkov, 2010; Philippon and Reshef, 2012). But there have been a number of deregulations following the intrastate banking, stretching over a time period from the 1970s to 2000 (Sherman, 2009; Cuñat and Guadalupe, 2009).

${ }^{5}$ There were several prior deregulations of the U.K. financial sector and some have described this as a more long-term process starting around 1979 when exchange rate controls and continued with the 1981 release of "the corset" of regulations on for example interest rates (Girouard and Blöndal, 2001). However, the Big Bang of 1986 is still clearly identified as the central and most important tipping point, empowering the previous changes and resulting in a new structure of the financial market entirely (Bellringer and Michie, 2014).
} 
represent a client and negotiate directly with the counterpart, rather than turning to a "market maker" to find a suitable deal, which increased the efficiency of the market immensely, and also decreased the costs associated with each trade (Clemons and Weber, 1990). The loosening on regulations regarding the roles of each firm increased both the competition and the potential firm size of the companies. Larger firms meant that risk could be decreased, or at least transferred to other parts of the firm (Llewellyn, 1990).

The impact of the Big Bang on stock market performance is generally conceived as large. The competitiveness of the London Stock Exchange as a whole increased, and the number of active firms increased while commissions and bid-ask spreads decreased. Daily stock market turnover nearly doubled in the first months after the reforms. ${ }^{6}$ Other major financial markets, such as Stockholm, Frankfurt, Paris and Milan, experienced crowding out effects and were later forced to adjust their own regulations (Clemons and Weber, 1990).

\subsection{The Japanese Big Bang in 1997-1999}

The Japanese Big Bang was proposed by the government in 1996 and its implementation occurred from November 1997 to April 1999 (Horiuchi, 2000; Gibson, 2000). ${ }^{7}$ The explicit aim with these reforms was to stop the financial outflow from Japan, partly caused by earlier deregulations of international capital flows, to stabilize the domestic financial markets and increase the competitiveness of the Tokyo Stock Exchange relative to the stock exchanges in New York and London (Toya and Amyx, 2006, p.192).

The main areas of deregulation concerned liberalization of rules regarding foreign participation (Lopez and Spiegel, 2014), owning structures of both financial subsidiaries and sister companies operated by banks (Toya and Amyx, 2006, p.193). It also included increased possibilities for the same firm to operate in different sectors of financial markets, most notably the same firm could act both as a commercial bank and as an investment bank (Takahashi, 2014). The implementation was designed as a "soft-landing" for the already established financial intermediaries (the incumbents), allowing them time to adapt before competition-increasing regulations were enforced

\footnotetext{
${ }^{6}$ During this era, the London Stock Exchange implemented a new, computerized trading system (SEAQ), which also improved the functioning of the market. It is plausible that the effect of this new technology could be captured as a part of the treatment effect of the Big Bang in the U.K. but since most other Western stock exchanges adopted similar technologies around this time this is not likely. Still, we have tried to assess this possibility by including measures of technology adoption, e.g., computerization, when constructing synthetic control groups, but without finding any clear effects.

${ }^{7}$ The final reforms (of the insurance sector) were delayed until 2001, but they are not as extensive as the earlier reforms (Gibson, 2000)
} 
(Toya and Amyx, 2006, p.195, 206). However, they were not a part of the decision making process, and the attitude of the incumbents were negative. This differed from the U.K., where the market actors favored the new policies.

During 1997 and early 1998, Japan was hit by the Asian financial crisis, and government injections of funds into the financial sector may confound the results during this period (Toya and Amyx, 2006, p.199-200). Until June 1998 several financial institutions, from insurance companies to major banks, were on the verge of bankruptcy and even more received governmental support. The support amounted to over 1.80 trillion yen (about 15 billion USD, according to the IMF exchange rate archive), and may have been effective in countering the negative impact on the financial sector.

\section{Why would Big Bangs raise top income shares?}

This section discusses potential mechanisms through which financial deregulation can influence top income shares. In the theoretical literature on the links between financial development and the income distribution, two different effects are discussed, one concerned with the extensive margin (the access to financial markets) and the other with the intensive margin (the rates of return for incumbents already involved in the financial market). ${ }^{8}$ The focus in this study lies on the intensive margin, since that is what may primarily impact the top income shares. ${ }^{9}$

The starting point for the intensive margin effects is that when the financial sector is liberalized this allows a higher degree of freedom in scale and scope of financial activities making financial markets more efficient. The efficiency gains raise returns, both among the financial market actors themselves and for non-financial corporations since they can be better diversified and take on higher risks to make higher returns (Llewellyn, 1990). The transmission of these deregulation effect onto top income shares may work through several channels, but two key mechanisms analyzed here are higher returns to the wealth managed by the financial sector, boosting capital incomes in the top, and higher earnings to highly paid financial sector employees.

\footnotetext{
${ }^{8}$ Extensive margin effects mainly work in undeveloped financial systems where inequality persists through generations because only those already with access to capital through inheritance will have the possibility to invest in human capital (Galor and Zeira, 1993) or entrepreneurial activities (Banerjee and Newman, 1993). When the financial sector develops and the access to loanable funds becomes universal, individuals from poor families will benefit relatively more, and inequality will decrease (Greenwood and Jovanovic, 1990).

${ }^{9}$ One possible source of extensive margin effects with relevance for this study is interjurisdictional mobility of high-income earners, leaving non-regulated financial centers for the U.K. or Japan after their respective Big Bangs. We are not aware of detailed sector-based evidence on worker flows across countries and therefor e abstract from this aspect at this stage.
} 


\subsection{Higher returns to wealth}

If financial deregulation makes financial services more efficient, then expected payoffs on capital and wealth managed by financial intermediaries will increase. This development will primarily benefit insiders when entry costs to financial markets are high (Greenwood and Jovanovic, 1990). Since the share of capital income in total income is typically higher among top income earners than in the rest of the population, and this also holds for the U.K. (Atkinson, 2007) and Japan (Morichugi and Saez, 2010), the higher wealth returns resulting from financial deregulation will benefit top income earners disproportionately and raise their relative share of all incomes in society.

Empirically, the evidence on a link between financial deregulation and wealth returns is mixed. Several studies have examined deregulation effects on overall market efficiency. Jayaratne and Strahan (1996) point at positive effects on real per capita income growth links in U.S. states that abolished bank branching restrictions deregulation in the 1970s and 1980s. Gerardi, Rosen and Willen (2010) found that the deregulation and securitization of U.S. credit markets during the early 1980s increased the efficiency of the market as measured by the degree of mismatch between credit supply and individual household spending on housing. Similarly, Clemons and Weber (1990) show that the U.K. Big Bang was followed by reduced transaction costs (lower trading fees and bid-ask spreads) and higher returns to investors. On the other hand, the recent study by Philippon (2015) of the long-run evolution of the efficiency of the U.S. financial system provide evidence on large increases in unit costs in banking services precisely during the period of wide-ranging bank deregulations in the 1970s a and 1980s.

\subsection{Higher earnings in the financial sector}

Another channel through which financial deregulation could drive top income shares is higher earnings of financial market employees. A number of studies indicate that financial sector employees are overrepresented in the top of the income distribution. For example, Kaplan and Rauh (2010) identify Wall Street top employees and partners of firms in the private equity, hedge fund and venture capital businesses and find that they constitute a substantial share of the top 0.1 percent of income earners in the US in 2004. Bell and van Reenen (2010) found similar evidence for the U.K., showing that 40 percent of those in the top percentile are working in the financial sector.

A link between deregulation and finance sector wages is suggested by several studies. Philippon and Reshef (2012) attribute most of the observed relative wage increases in the U.S. since the 1970s to financial deregulations. The share of top decile income earners that were employed in financial industries increased from about one hundredth in 1980 to about one tenth in 2009. This trend reflects the combined outcome of higher 
relative wages and an increase of the number of highly remunerated finance people. Philippon and Reshef (2013) find similar patterns in other countries and historical eras and Boustanifar et al. (2016) find, using cross-country regressions, that financial deregulation is the most important driver for relative wage and skill intensity of finance industry workers.

Looking more closely at potential channels accounting for these observed trends, several explanations have been proposed. Some studies point at firm size effects, emphasizing that as restrictions on financial firms to expand their business to other financial sectors are lifted, which happened in both the U.K. and Japan after their Big Bangs (Gibson, 2000; Clemons and Weber, 1990), the size of firms and industry concentration may increase and boost the remuneration to employees and managers in the financial industry (e.g., Gabaix and Landier, 2008; Hubbard and Palia, 1995).

Financial deregulation could also affect the structure of compensation to managers. Crawford, Etzell and Miles (1995), Becher et al. (2005) and Cuñat and Guadalupe (2009) find that the U.S. banking deregulations during the 1970s and 1980s made bank executive compensation more pay-performance sensitive, including more stock options and other performance-related remunerations. Coupled with the documented rise in stock market returns during the 1980s throughout the Western world, which was the result of a number of contemporaneous developments related to regulation, technology and globalization, the incentive-pay schemes were more profitable than before the deregulation periods. Some scholars, e.g., Bebchuk et al. (2002), have raised concerns about these stock option contracts being designed not according to optimal contracting theory (which would provide the best incentives for the executive) but rather as a concealed means of rent extraction for the executive manager.

\section{Estimation methodology and data}

\subsection{Synthetic control method}

A general challenge for cross-country comparisons, which in particular holds for studies trying to link financial deregulation with inequality outcomes is to convincingly show what the counterfactual would look like. A potential solution to this challenge is the recently proposed synthetic control method (Abadie et al., 2010). The idea is to construct a synthetic country (which is actually a weighted average of all untreated countries) that has identical pre-treatment characteristics in terms of outcome and control variables to the treated country. The estimation of the treatment effect is to compare the post-treatment outcome in the treated country to that of the synthetic control group (i.e., the counterfactual). 
There are several advantages with using the synthetic control method (we discuss the problems further down in this section). The method is more efficient than a regression when only one country is treated, and when the pre-treatment characteristics of that country is not similar to the average in the group. Using a mathematical algorithm to construct control group is a hand-tying strategy to prevent that the control group is not ambiguously chosen by the authors. The method also shows exactly which control countries are being used in the analysis, which can be hard to determine from a regression analysis. Moreover, a combination of control countries also reduces the risk of a single confounding event affecting the results compared a standard difference in difference approach.

We use a total of $J$ countries to estimate the effect of deregulation, where the first country in the set is the treated county, and countries 2 to $J$ are the donor pool from which the synthetic control group will be created. The donor pool consists of all untreated OECD countries in our dataset.

Let $Y_{j t}^{s}$ be the share of income received by the top $s$ percentile for country $j$ for each period from the start, $t=1$, to $t=T$. For the treated country $(j=1)$, the financial deregulation begins at time $T_{0}, 1 \leq T_{0} \leq T$. For $t \geq T_{0}$, the top income shares observed for $Y_{1 t}^{s}$ are affected by the financial deregulation. The treatment effect of the deregulation, $\alpha_{1 t}$, is the difference between the treated and the untreated (potential) outcome, i.e., $\alpha_{1 t}=Y_{1 t}^{s}-Y_{1 t}^{N s}$, where $Y_{1 t}^{N s}$ indicates the potential outcome for the treated variable (it is not possible to measure $Y_{1 t}^{N s}$ directly).

In order to evaluate this treatment effect, an estimate of the counterfactual outcome is necessary. Suppose the potential outcome can be modelled as:

$$
Y_{1 t}^{N s}=\delta_{t}+\boldsymbol{\theta}_{t} \boldsymbol{Z}_{\mathbf{1}}+\boldsymbol{\lambda}_{\boldsymbol{t}} \boldsymbol{\mu}_{\mathbf{1}}+\epsilon_{1 t},
$$

where $\delta_{t}$ is a time-fixed effect, $\boldsymbol{Z}_{\boldsymbol{j}}$ is a vector of control variables that are important to the evolution of top income shares, $\boldsymbol{\mu}_{\boldsymbol{j}}$ is a vector of unobserved factors affecting the top income shares (but does not cause the financial deregulation in question), and the $\epsilon_{j t}$ is an idiosyncratic shock. If this holds, the potential outcome is affected by a number of variables, both observed and unobserved. It is possible to estimate the counterfactual if the same variables (both known and unknown) have the same effect on the outcome variables in other countries, and in other times. This means that a weighted average of the untreated countries can be used for equation (2) to hold:

$$
\sum_{j=2}^{J} w_{j} Y_{j t}^{N s}=\delta_{t}+\boldsymbol{\theta}_{\boldsymbol{t}} \sum_{j=2}^{J} w_{j} \boldsymbol{Z}_{\boldsymbol{j}}+\boldsymbol{\lambda}_{\boldsymbol{t}} \sum_{j=2}^{J} w_{j} \boldsymbol{\mu}_{\boldsymbol{j}}+\epsilon_{i t}
$$


for some vector of weights $\left(w_{2}, \ldots, w_{J}\right)=\boldsymbol{W}$, where each $w_{j}$ can vary between 0 and 1 , and the sum of all country weights is one. If so, Abadie et al. (2010) show that if a vector $\boldsymbol{W}^{*}$ can be chosen so that all weighted sums of control variables and the pre-treatment top income shares match the treated country:

$$
\begin{aligned}
\sum_{j=2}^{J} w_{j}^{*} \boldsymbol{Z}_{j} & =\boldsymbol{Z}_{\mathbf{1}} \quad \text { and } \\
\sum_{j=2}^{J} w_{j}^{*} Y_{j 1}^{s}=Y_{11}^{s}, \sum_{j=2}^{J} w_{j}^{*} Y_{j 2}^{s}=Y_{12}^{s}, & \ldots, \quad \sum_{j=2}^{J} w_{j}^{*} Y_{j T_{0}}^{s}=Y_{1 T_{0}}^{s}
\end{aligned}
$$

then (2) holds, even though $\boldsymbol{\mu}_{\boldsymbol{j}}$ is unobserved, the weighted average of the donor pool can be used as an unbiased estimator of the potential outcome, and $Y_{1 t}^{s}-\sum_{j=2}^{J} w_{j}^{*} Y_{j t}^{s}=$ $\hat{\alpha}_{1 t}$ represent an estimator of the true treatment effect.

According to the appendix in Abadie et al. (2010), the sums in (3) and (4) only need to hold approximately for the weighted average to be a good estimator. To solve the conditions in (3) and (4), a nested penalty function is set up to optimise the fit to each control variable and pre-treatment year when choosing $\boldsymbol{W}^{*}$. In practice, only a selected years of $Y_{j t}^{s}$ are used, as not to overfeed the optimization function. The nested penalty function includes weights for the relative importance of each control variable in the penalty function. ${ }^{10}$

A synthetic control group (SCG) is then calculated using the country weights, and this is used as a counterfactual in the economic analysis. However, the approximation must be close enough to the treated country's history of control parameters and previous top income shares. There is no clear cut-off suggested for how much divergence can be allowed in the estimations, and this match is one issue to address in the discussion of the results.

There are some well-known problems with the synthetic control method that we try to address in the robustness section below. First, making inference differs from standard significance testing since the data available is used to construct the counterfactual instead of standard errors for confidence intervals. Abadie et al. (2010) propose using repeated placebo tests as basis for an inference-like testing procedure. By repeatedly creating synthetic controls for all countries in the sample, and estimating the gap in top income shares after the start of a fictional deregulation for all of them, it is possible

\footnotetext{
${ }^{10}$ If one control variable only has a very limited impact on top income shares, while another, has a large impact, weights for all controls are specified in $\boldsymbol{V}$ as to make sure that the synthetic control group is very well matched in terms of tax rates, but perhaps less so in growth. The nested optimization problem first optimize the control weights matrix $\boldsymbol{V}$, then the combination of countries that best match these controls, $\hat{\boldsymbol{W}}^{*}$, is chosen (Abadie et al., 2011).
} 
to determine how likely it is (within this sample) to receive by chance a deviation as large as the deviation of the treated country. From that one can conclude how likely it is that the parallel trend assumption holds for this population.

Second, the selection of control variables to construct synthetic controls must be checked. We do this by changing the composition of $\boldsymbol{Z}$ to ensure the treatment effect is stable. This procedure is not suggested by Abadie et al. (2010, 2011), but we propose it as a way to offer a more transparent view of how the results may vary along with minor changes in the specification of $\boldsymbol{Z}$. By using different combinations of control variables and time periods in the optimization function, different synthetic controls will be calibrated. If all of these are similar to the baseline control trend, the results are believed to be more robust.

Third, a common critique of the synthetic control method is that its exclusive datadriven focus on pre-treatment trends effectively implies an assumption about parallel post-treatment trends in the control variables of treated and synthetic control countries. Violating this assumption could severely bias the results in unforeseeable ways. We recognize this issue and closely examine the post-treatment trends of all control variables in treated and control group countries.

\subsection{Data}

\subsubsection{Top incomes}

Data on top income shares come from the World Wealth and Income Database (WID). These series are shares of total gross income before taxes and most transfers going to different groups in the top of the income distribution, from the top decile to the top 0.1 percentile. A major advantage with the top income share data is that they stem from very similar source, tax statistics, and have been computed using the exact same methodology, which make them highly comparable over time and also across countries. ${ }^{11}$

The country donor pool is restricted to OECD countries and among those there are top income data available in the WID for 18 countries. The synthetic control method depends on a full matrix of pre-treatment observations to calculate the optimal control group and missing data for single years can disturb the calculation. Some countries are therefore excluded, typically where data are lacking for several subsequent years, but for some countries linear interpolations have been used, to make them fit the criteria for the donor pool. ${ }^{12}$ We restrict the pre-treatment period to begin in 1971 for the

\footnotetext{
${ }^{11}$ See Atkinson and Piketty (2007, 2007), Atkinson, Piketty and Saez (2011) and Roine and Waldenström (2015) for further descriptions and discussions about the merits and problems with the top income data.

${ }^{12}$ We do this for countries with only one stray year missing, such as Denmark (in 1973), or for
} 
U.K. and 1981 for Japan in order to be able to include as many countries as possible in the donor pool. This gives 15-17 years of pre-treatment to optimize the synthetic control group. Modifications to each country's data series, if any, are described in the appendix table A1.

Information about income sources, e.g., labor and capital, are scarce in WID and we are unable to make any systematic analysis of the importance of earnings or capital incomes for the impact of financial deregulation. Nevertheless, there is some evidence on their importance in the income top in the U.K. and Japan. Atkinson (2007) estimates that the top percentile income shares stems since the 1970s for the most part, perhaps two thirds, from labor earnings and the rest investment income and other sources. Data for Japan are somewhat richer and Moriguchi and Saez (2008) report that also in Japan earnings comprise most of top percentile incomes. Figure 1 shows these patterns for the U.K. and Japan over the analyzed periods.

[Figure 1 about here]

\subsubsection{Control variables}

In order to create a good synthetic control group, a proper selection of control variables is key. We select variables which represent the most important determinants of top incomes according to the literature on inequality and financial development. In addition, we include controls that affect the likelihood of a large-scale financial deregulation, since this event is not necessarily fully exogenous without including them. ${ }^{13}$

Four main categories of control variables are considered. First, tax rates and government spending are included as they are deemed important for both pre- and post-tax income inequality (Roine et al., 2009; Piketty et al., 2014). In the baseline model, we use statutory top marginal income tax rates from Piketty et al. (2014). Second, the literature on the links between income distribution and growth (see, e.g., Galor and Zeira, 1993) suggests that both the level of GDP per capita and growth rates are important to determine income distributions at a broader level, and they will be controlled for using World Bank data. Third, labor market and political institutions can affect income inequality (Korpi and Palme, 1998; Atkinson, 2007), and they may also affect the timing of financial deregulations (Pagano and Volpin, 2005). While it is difficult to capture all aspects of the relevant institutional setting, our baseline specification controls for legal origin (La Porta et al., 1997), the level of employment

countries with bi-annual data, such as Switzerland.

${ }^{13}$ The robustness section includes additional control variables, including measures of trade openness and variants of the controls used in the baseline specification. 
protection (Nickell, 2006) and the political orientation of the executive in the pretreatment period available in the Database of Political Institutions (Keefer, 2012 and complemented by us for pre-1975 years).

A fourth category of controls addresses the endogeneity of financial deregulation. The possibility that the Big Bangs were themselves caused by the variables driving inequality change (or even by the inequality change) is to some extent handled by the synthetic control group methodology. By accounting for parameters that may have affected the likelihood of a financial deregulation as well as changes in the income distribution when selecting control group, the counterfactual should ideally possess the same probability of an unexpected increase in the relevant top income share as well as having a Big Bang. One such factor is potentially the previous state of the financial sector; if the financial sector is heavily regulated, or works poorly, politicians may want to improve it drastically by "giving it a 'big bang'". Finding a good measurement on the performance of financial markets is difficult, especially for the U.K. as many datasets do not reach far enough back in time. The Financial Development and Structure Dataset by Beck, Demirgüç-Kunt and Levin (2010) does not include any data on the size or efficiency of the British financial sector until after 1989 but we can use it in the analysis of the Japanese Big Bang. The London Stock exchange is not available before 1997, so in order to capture the relevant trends in the U.K. we instead use de jure indexes of financial market regulation in order to ensure that the preconditions are the same in treated and control countries. One of the most comprehensive measures is the Quinn (1997) index, which takes the qualitative aspects of specific regulations into account and (Vlachos and Waldenström, 2005). This index will be used in the baseline specification for the test of both the U.K. and the Japanese Big Bang. ${ }^{14}$

Note that the Big Bangs were not introducing basic freedoms of transaction, which were already in place. They instead meant additional lowering of entry barriers and firm size regulations, which gave an extra boost to the country in terms of financial market international competitiveness. The other OECD countries are experiencing deregulations during the time period, which means the counterfactual will not consist of countries with a static financial sector, but rather the "big bang" will be compared to a "normal" financial market evolution during the time period.

[Table 1 about here]

\footnotetext{
${ }^{14}$ Other datasets and measures of financial deregulation are used in robustness tests presented in the robustness section below, and they are extensively discussed in appendix section A.4.
} 


\section{Results}

In this section we present the main results of our analysis, beginning with a description of the composition of the synthetic control groups, continuing with the baseline results for the top income shares and for intermediate groups within the top and finally we examine the characteristics of the synthetic control groups.

\subsection{Baseline results}

Each synthetic control group is obtained using a convex combination of countries, is optimized over previous trends of top income shares and the control variables. New calibrations are made for each top income share why the control groups may differ across them. ${ }^{15}$

Tables 2 and 3 present the combinations used in the baseline estimations. In the U.K. case, the most frequent used countries in the synthetic controls are Australia, Canada and Ireland, which may not be surprising given their shared institutional preconditions in terms of language and legal origin (recall that the U.S. was left out of the donor pool in the U.K. estimation). Note that Japan is also in the U.K. control group in the top 5 percent case, and in order to avoid contaminating the controls with Big Bang-related outcomes we restrict the selection to the pre-1997 period. In the Japanese case, the most common synthetic control countries are Spain, Switzerland and the U.S. The fact that the donor pool lack Asian countries may be a problem, but since the modern Japanese legal system actually has a lot of its roots in German law (La Porta et al. 1997), and the early Japanese postwar reforms were led by the U.S. (Williams, 1988) it is reasonable to believe these countries are a good match.

[Table 2 and 3 about here]

We now turn to the main results of the study, namely the effect of financial deregulation on top income shares. Figure 2 depicts top income shares in the U.K. (solid line) and the synthetic control groups (dashed line) fifteen years before and after the 1986 Big Bang in the U.K. The tests suggest that income shares going to U.K. top income fractiles increased relative to the synthetic control group top shares as a consequence of the Big Bang. The size of this "gap" between the true U.K. outcome and the synthetic trend is expressed in percentage deviation terms in Figure 3, showing that top income shares increased by between 20 and 30 percent. The impact was not instantaneous

\footnotetext{
${ }^{15}$ As an alternative approach, we also constructed a single synthetic country to plot the counterfactual trend for all top income shares, see appendix section B.3. A unified synthetic control across top income fractiles is theoretically more justifiable only as long as the same unobservables are expected to affect the different top income shares similarly. However, the results indicate considerably worse matches in pre-treatment trends, but even so the Big Bang effects are still notable.
} 
but materialized over the first four years after the reform, reaching a new level around 1990. ${ }^{16}$ There is a notable one-year spike in the synthetic control top 1 and top 0.1 percentile income shares in 1988 which almost nullifies the Big Bang-effect in the first years but not after a five-ten year period. This is caused by a single outlier observation in the Australian data. The implications and robustness of this spike will be discussed below.

[Figures 2 and 3 about here]

The main results for the Japanese Big Bang in 1997-1999 are shown in Figures 4 and 5. The Japanese synthetic controls fit the pre-treatment trends very well, and after the deregulation the true trend and the SCG start deviating quite notably in all the top fractiles. The size of the deregulation effect in Japan is indicated in Figure 5, showing that the Japanese top income shares were by the mid-2000s over 10 percent higher than they would have been in the absence of a Big Bang. This increase is equivalent to a 4 percentage point increase in the share of earnings allocated to the top 10 percent of the population, increasing their share from a synthetic value of about 37 percent to 41 percent a few years after the reform.

[Figure 4 and 5 about here]

Inspecting the match of pre-treatment trends between treated and synthetic controls is a first check of the goodness-of-fit of these results (we present other checks in the robustness section below). In the case of Japan, the Japanese synthetic control groups appear to fit the pre-treatment trends quite well, which is reassuring.

In the case of the U.K., the effect of the Big Bang appears to materialize two-three years before the actual reform, especially when looking at the top 10 and 5 percentile groups. Such pattern either suggests some form of anticipation effects, e.g., with financial firms starting to raise wages or hire new key staff to stand prepared, or perhaps more likely that the control groups are not able to fully account for the relevant pre-treatment variation, which could be due to a range of factors. For example, we know that several minor financial deregulations occurred in the U.K. and in most other Western countries during the early 1980s (Girouard and Blöndal, 2001), and to the extent that these are not fully captured by the Quinn index of financial liberalizations there is an omitted variable bias. It should be noted that we have tried several different indexes of

\footnotetext{
${ }^{16}$ Note that there is an additional jump in the series in 1990, which could be due to time series break stemming from a tax reform changing, among other things, tax units from households to individuals (Atkinson, 2007).
} 
financial and stock market regulations (see appendix Figure A1) and the Quinn index still performs best.

\section{$5.2 \quad$ Intermediate top income shares}

The heterogeneity of top income earners is one if the main finding in the past top income literature and this can bear important clues to the forces at work in our estimates. In particular, top-income earners with incomes up to the 99th income percentile tend to be largely well-paid employees with almost all of their income in the form of wages and salaries. In the top percentile and especially the top 0.1 percentile, however, top executives and super-rich individuals are predominant and large, perhaps the major, share of their income comes from capital. In other words, if changes in certain parts of the top can be identified, this could indicate through which mechanisms the top incomes are affected by the deregulations.

In this section we split up the top into intermediate fractiles and remake the analysis creating separate synthetic control groups for each of them. For example, the top 10 decile is divided into a lower and an upper half and the impact of financial deregulation on the lower half is tested by constructing a synthetic control group from other countries' trends in the percentile 90 to 95 . Synthetic controls are created in a similar fashion for the top vintile (splitting between its bottom four percentiles and the top percentile) and the top percentile (splitting between the lower 9 thousandth of the top 0.1 percentile). ${ }^{17}$

Figure 6 shows the results for the intermediate top fractiles. Evidence of somewhat diverging patterns diverge across the U.K. and Japan. In the U.K. case, the deregulation impact documented for the top decile is accounted almost totally by the top 5 percentiles whereas the bottom half of the top decile did not change much. Splitting up the top 5, in turn, shows that the top percentile and the next 4 percentiles stand for almost equal amounts of the total income share rise. Looking within the top percentile, finally, shows that its increase is driven by the lower 9 lower thousandths whereas the rise in the top 0.1 percentile is relatively smaller and above all less discernable due to the spike in Australian top incomes driving in the synthetic control.

These patterns offer little support to models focusing on increased wealth returns to the super-rich, at least to the extent that most of these individuals are in the most exclusive top 0.1 percentile. The results instead level with theories about increased

\footnotetext{
${ }^{17}$ The new synthetic controls consist of a new combination of countries from the donor pool and the details of these new controls are presented in the appendix, table A9 to A11. This has the consequence that the lower and upper half of the top 10 percent does not add up to the same result as the full top 10. This would only be the case if the trend for the British (or Japanese) top 5, top 10 and the lower 5 percent would all be best matched by the exact same combination of other countries, which is usually not the case.
} 
compensations to managers or other employees in the financial sector, whose incomes increased due to efficiency gains and higher profitability among the financial firms.

Turning to Japan, the intermediate groups in Japan tell a somewhat different story. Here, the Big Bang-effect on the top decile income share is equally accounted for by the lower and upper halves. Decomposing the effect within the top 5 percentiles, moreover, shows that most of it is attributed to the lower 4 percentiles while the top percentile contributes relatively little. Finally, looking within this limited effect on the top percentile shows that there is basically no contribution at all coming from the top 0.1 percentile.

The Japanese Big Bang thus seems to have boosted incomes for top-earners below the highest percentile, and the most likely explanation is that the Japanese financial deregulation had a positive effect on the incomes of financial sector employees. This increase would show among those "just entering" the top 10 percent, which would suggest the broader top income measurements (the lower half of the top 10 percent or maybe the low top 5 percent) would be the most affected. The explanation of employment compensation also seems to be the most likely for Japan since Morichugi and Saez's (2010) decomposition of the top 1 percent for Japan show an increased trend in employment income, though not in capital income, after 1997 (see figure 1b).

It is also possible that the use of high-powered incentive-pay schemes increased more in the U.K. than in Japan after the deregulations, which would suggest a concentration of the relative income increase to the very top. Other reasons than financial deregulations have been suggested to explain this increase (e.g., Piketty et al., 2014; Bebchuk et al., 2002), and it is possible that these factors interacted with the financial deregulation in the U.K. At this point, we do not possess of enough detailed data to test this hypothesis.

[Figure 6 about here]

\subsection{Control group composition and control variables}

Examining the composition of the synthetic control groups and the average levels of control variables in the treated and SCG countries offer important checks on the goodness-of-fit of the SCG estimation procedure according to the method guidelines of Abadie et al. (2010).

Concerning the number of countries included in the SCGs, they are between two and four in the main analysis. While this may at first sight seem low, it is actually not a problem; when constructing SCGs we tested all possible combinations of all 
of the countries in the donor pool. If only a few countries are included in the final control this is because they provide the mathematically best solution in the sense that they minimize the difference between the true and synthetic control variables and top income trend in the pre-treatment period.

As for the control variables used, Table 4 reports pre-treatment means of the control variables of SCGs, the treated country and, for comparison, the entire donor pool. The more controls, in combination with a high emphasis on fit in terms of previous top income shares, the worse each separate control variable will match that of the treated country. ${ }^{18}$

[Table 4 about here]

The quality of the match between treated countries and synthetic control groups is not homogenous across all cases. For the U.K., the top decile control group matches very well, perhaps with exception for GDP per capita growth which has a poorer match than the overall mean among donor countries. The U.K. Quinn index is higher than the mean, and all of its synthetic controls, and even though Japan lies slightly lower in this aspect, the stock market capitalization in Japan is very high, even before the Big Bang. With regards to the discussion on the endogeneity of financial deregulations, it is reassuring to see that there is no indication of the U.K. or Japanese financial markets under-performing compared to their control groups. The differences in means between Japan and the control groups for the top 10 and top 5 income shares are worrying. Only two control variables (legal heritage and the stock market capitalization) in these cases provide a better match than in the donor pool. The other two control groups for Japan preform slightly better.

The overall picture of the goodness-of-fit with respect to the control variables is therefore mixed. While it looks well for the U.K., it looks worse in the Japanese case. In general, the fit is not as good as Abadie et al. (2010) recommend for getting a reliable synthetic control and we therefore continue by conducting robustness tests to get further information about the quality of the estimates.

\section{Robustness analysis}

\subsection{Placebo Tests}

As discussed in Section 4, the most common way to test the statistical significance of a synthetic control estimator is to use placebo tests, which here means to perform the

\footnotetext{
${ }^{18}$ This comes out of the construction of the nested optimization function, which minimizes the sum of squared deviations.
} 
tests as if it was the non-treated countries that had been treated. For each country from the donor pool then, a synthetic control group is calculated even if there is no real deregulation to test for. Since the number of countries in the sample is limited, there will be too few placebo tests in total to test the significance of the results on a more than ten percent confidence level.

This test gives an indication of whether it is likely that a similarity in pre-treatment trends between the real country and the synthetic control group would have continued in the absence of treatment, which is the underlying assumption when interpreting the results in section five. If countries where no treatment is known deviates from the synthetic trend after the period over which the control group is optimized, it is likely that this would also be true for the U.K. and Japan even in absence of the Big Bangs. If, on the other hand, all other countries seem to behave as their synthetic controls, it is less likely that the increase observed for British and Japanese top income shares relative to the synthetic controls occurred by chance.

There is a maximum of twelve countries in the U.K. donor pool, and thus twelve placebo tests that will be run for each income group. For Japan, the number of donor pool countries is 13 but some countries lack data for some income groups which leads to somewhat fewer tests. Having a small number of control countries is problematic, since it does not allow for excluding countries with a too bad control group in terms of pre-treatment fit (which is done by Abadie et al., 2010). ${ }^{19}$

Figures 7 and 8 present graphical representations of these placebo tests, where each grey line represents the deviation from the synthetic control group for a donor pool country and the baseline case is the thicker black line. The deviations from the synthetic trend for U.K. after 1986 and Japan after 1998, where an increase is expected, is simply compared to the other countries, where no change is expected. ${ }^{20}$ Furthermore, Table 5 presents a numeric representation based on these placebo tests of the likelihood that there will be any such extreme deviations from the synthetic control group trend by pure chance, and not as an effect of the big bangs. If deviations between the non-treated countries and their synthetic controls are large, it is less reasonable to assume that the Japanese and British counterfactual trends can be described by these synthetic control groups.

\footnotetext{
${ }^{19}$ The consequence is that the total spread in the post-treatment time period might in fact only be a large spread in the pre-treatment, caused by a general failure of the synthetic control method for some outlier country, not showing the true probability of divergence.

${ }^{20} \mathrm{Had}$ each synthetic control group offered a perfect fit, all the grey lines ought to be equal to zero both before and after the fictive treatment. Apparently, they are not, but the more extreme the true treatment effect is compared to these placebos, the less likely it is that the outcome for U.K. or Japan was a coincidence.
} 
[Figures 7 and 8 about here]

The U.K. placebo results indicate an overall high level of significance of the estimated deregulation effect on inequality. As shown by the figure, the deviation from the SCG shares is clearly very extreme in the positive deviation bound. The effect is stronger in the subgroups within the top that we saw above were relatively important. For example, the effect is more notable on the top 5 percent share than it is on the top 0.1 percent share, which thus suggests that the results for top 5 percent is less likely to have been caused by chance. Looking at the implied "p-values", they are overall quite small for all groups except for the top 0.1 percentile where the effect is less robustly estimated.

For Japan, the placebo results are somewhat weaker than for the U.K. This can to some extent be explained by the fact that the similarity between the Japanese pretreatment trend and its synthetic control is much better than many of the placebos. If the synthetic control group does not match a country's trend very well over the period it is optimized, it is less likely that their trends would coincide in the period after.

All possible placebo tests are included in the "p-value" calculation, which mean the problem with bad control variables for some countries increase the spread. Due to the limited number of countries in the sample (discussed above), no placebo test is dropped, even though the pre-treatment fit is very bad for some placebo countries. Abadie et al. (2010) drops such bad placebo observations from their test. This said, the placebo figures and the derived "p-values" suggest that also in Japan did the financial deregulation increase top income shares. The increases in top 10 and 5 percent income shares thus appear to be robust, especially immediately after the reform during the early 2000s.

[Table 5 about here]

\subsection{Selection of variables to construct synthetic control}

The selection of variables used when constructing the baseline synthetic controls (Table 4) do, of course, not represent the full set of potential top income share determinants. Other measures may be more accurate, or some measure may create a bias in the selection of the synthetic control group. Therefore, a number of different combinations of control variables have been used as a robustness check for this particular combination. $^{21}$

\footnotetext{
${ }^{21} \mathrm{~A}$ full description of the pool of control variables used in this robustness test is presented in the
} data appendix, table A3. 
Figures 9 and 10 present robustness calculations where the black lines represent the baseline results and the different patterns for the grey lines represent different time sets. The robustness lines are based on 40 different combinations of variables, combined with three different set of years used to control for the top income time trend. (The specific years are listed in appendix table A4.) Altogether, we thus have 120 different synthetic control groups for each country and top income share. ${ }^{22}$

[Figures 9 and 10 about here]

The baseline results seem to stand up well to the alternative specifications. The U.K. baseline synthetic trend lies in the middle of the span of control specifications. The main non-robust feature seems to be the "spike" in the top 1 and 0.1 percentile synthetic control group just after 1986, actually caused by an outlier in the Australian data, which is indeed sensitive to different weights on Australia. Hence, the delayed effect for the highest income shares in the U.K. may be caused by this outlier in the Australian data, rather than a lagged treatment effect. Overall, the choice of control variables does not seem to be driving the results, which is a sign of robustness.

Finally, we also restrict the U.K. controls to only match the era of the Thatcher regime during 1976-1986, represented by grey, dashed lines in figure 9. The right-wing policies are thereby given a full weight in this specification, which is preferable to the baseline results if it is the case that top income shares respond only to short-term political factors instead of longer term economic indicators. However, the results do not produce a better fit than in the baseline specification, suggesting that both longand short-run factors matter for the determination of top income shares. ${ }^{23}$

Looking at the Japanese baseline synthetic controls, they are all in the upper bound of the span of alternative control groups, except for the top 0.1 percent. This indicates that the Japanese results may actually underestimate the true effect of the Big Bang. In the case of the trend for the top 0.1 percent, there is one of the control group specifications seems to match the post-treatment trend very well, with no indication if a Big Bang.

\footnotetext{
${ }^{22}$ The reason that there are less than 120 lines in each graph is because of the nesting where some control variables are given a very small weight and thus may result in an optimization problem which is basically identical to a specification without that variable and thus their lines coincide (see further Abadie et al., 2011).

${ }^{23}$ See further the discussion in section 6.2 and the results in the appendix section B1. Specifically, one should compare control variable fits in tables 4 to those in A8 and the pre-treatment trends in figures 2 to the trends in A5.
} 


\subsection{Parallel trends in post-treatment period}

A central assumption in the synthetic control group method is that trends in treated and control countries are assumed to be parallel after the time of the treatment. This comes from the fact that control groups are formed by purely data-driven factors instead of, as is many other estimation approaches, including countries based on their observed economic or institutional characteristics. Consequently, if important innovations occur in control variables after the treatment this could severely bias the synthetic control group estimates in unforeseeable ways.

We take this issue seriously and investigate post-treatment trends of all the control variables used in constructing the synthetic controls. Figures 11 and 12 graphically depict the development of each of these control variables, starting from the treatment year and up to 15 years thereafter in both treated and control countries.

[Figures 11 and 12 about here]

In the case of the U.K., almost all variables in Figure 11 exhibit reassuringly parallel developments, with two exceptions. The first is the capital-account liberalization index of Quinn (2003), which increases in the synthetic control countries relative to the U.K. This could indicate more rapid financial deregulation in the control countries and therefore a spill-over of the treatment effect on the control group outcome, which would mean that we underestimate the inequality boost of the Big Bang.

A more important deviation in Figure 11 is that top marginal income taxes fell relatively sharply in the U.K. shortly after the Big Bang while they decreased less and at a lower pace in the synthetic control countries. This development is apparent both when using statutory top rates, our main measure, and the additional measure of marginal income tax rates paid by people earning five times GDP per capita (Rydqvist, Spitzman and Strebulaev, 2014). By 1990, the statutory top marginal tax rate had dropped by one third (from 60 percent to 40 percent) since 1986 in the U.K. and roughly half (between one seventh and one fourth) of that in the different synthetic control groups. Gauging the effect of this drop on incomes is difficult, but with a standard income tax elasticity of 0.2 this differential tax drop would mean that one seventh of the recorded Big Bang effect is actually due to the tax reduction. ${ }^{24}$ Now, Piketty et al. (2013) find that top earners are relatively more responsive to tax changes, with elasticities of between 0.6 and 0.8 , and with such high sensitivities about half of the deregulation effect would be due to taxes.

\footnotetext{
${ }^{24}$ Multiplying 0.2 by half of the percentage tax reduction in the U.K., $0.5^{*} 0.33=0.165$ gives 0.033 , which is about one seventh of the measured Big Bang effect of 20-25 percent.
} 
However, there is reason to believe that the confounding tax effect is not that large in the U.K. case. One is that the Piketty et al. results are confined to explain the variation of the top percentile, a group that is dominated by the top 0.1 percentile. By contrast, we find deregulation effects primarily in the groups below the very top. Furthermore, looking at the actual U.K. income tax rates over this period paid by people in the different parts of the top decile, the tax changes in 1988 was not as large for incomes below the top percentile. Another reason for making a distinction between the very top and the rest of the top decile is that capital incomes matter much in the very top, and several studies show that top capital incomes are relatively taxsensitive through short-term income shifting (Goolsbee, 2000; Gordon and Slemrod, 2000) which ought to be less common among well-paid finance employees. In other words, it is thus likely that a confounding U.K. income tax effect indeed mitigates the estimated Big Bang effect on top incomes, but not by much.

Turning to Japan, we find a similar strong case for post-treatment trends in control variables being roughly parallel. There is some degree of variation in the employment protection laws, which seem to have become relatively laxer in Japan relative to the synthetic control, but the difference is still relatively small.

The most apparent deviation appears, as in the U.K. case, in the top marginal income taxation. The top statutory tax rate fell in Japan soon after the Big Bang whereas it changed less in the control countries. However, this deviation seems to be unique to the extreme top of the distribution and thus with little relevance to our main deregulation effects estimated above. Looking at the marginal income tax rates paid by people earning five times GDP per capita, the trends are essentially equal. Furthermore, Saez and Moriguchi (2008) report in their appendix that the tax rates paid by top wage earners, i.e., those groups our previous analysis found were those mostly affected by the financial deregulation, changed remarkably little during and after the Japanese Big Bang.

Overall, the assumption of parallel post-treatment trends in control variables is supported by the data in most relevant respects. The only major deviation is the large drop in U.K. top tax rates immediately after the country's Big Bang, but as we argue there is little ground for believing that this change has any important biasing effect on our main findings.

\section{Concluding remarks}

This paper set out to empirically analyze the relationship between financial market deregulation and top income shares. While the relationship between finance and in- 
equality has, of course, been studied before, the unique contribution of the study lies in using the novel synthetic control method for quasi-experimental evaluation to causally identify how top income shares were influenced by the Big Bangs of financial deregulations that occurred in the U.K. and Japan during the 1980s and 1990s.

Our main finding is that, compared to synthetic control groups, the income shares of top earners increased substantially in both the U.K. and Japan as a result of the Big Bangs. Five years after the deregulation, the effect on the top decile was an increase of 20 percent in the U.K. and 15 percent in Japan whereas the top percentile increased by almost 30 percent in the U.K. compared to 10 percent in Japan. The measured effect was strongest within the upper half of the top decile in the U.K. while it in Japan was strongest in all of the top decile except for the top 0.1 percentile. We make several robustness checks, examining the selection of variables when constructing synthetic control groups, making placebo tests and inspecting post-treatment trends of control variables in treated and synthetic control countries. Overall, these checks confirm our main findings. The most important qualification is a potential confounding effect coming from sizeable income tax reductions in the U.K. soon after the Big Bang. A close examination of the relevant institutional and fiscal characteristics suggests, however, that this tax effect has at most a limited influence on our findings.

Seeking explanations to the observed patterns, we find that the most plausible works through the labor market. Previous studies show that financial deregulations tend to have a positive impact on the earnings of financial sector employees (Philippon and Reshef, 2012; Boustanifar et al., 2016), and this goes well together with what we observe. In both the U.K. and Japan, top incomes primarily consisted of wage income at this time, and our measured deregulation effects are strongest among top earners below the very top of the distribution which is typically dominated by capital-income earning super-rich individuals.

Needless to say, a study with a scope such as this leaves many stones unturned. It is, for example, likely that the distributional impact of a regulatory shock to the financial system differs depending both on the nature of the shock and the institutional setup of a particular country. We hope that our work will stimulate further research on such particularities since it would further advance our understanding of the role of institutions for income inequality. 


\section{References}

Aaberge, R., \& Colombino, U. (2013). "Using a Microeconometric Model of Household Labour Supply to Design Optimal Income Taxes." Scandinavian Journal of Economics, $115(2), 449-475$.

Abadie, A., Diamond, A., and Hainmueller, J. (2010). "Synthetic Control Methods for Comparative Case Studies: Estimating the Effect of California's Tobacco Control Program." Journal of the American Statistical Association 105(490): 493-505.

Abadie, A., Diamond, A., and Hainmueller, J. (2011). "Synth: An R Package for Synthetic Control Methods in Comparative Case Studies." Journal of Statistical Software 42(i13).

Abadie, A., and Gardeazabal, J. (2003). "The Economic Costs of Conflict: A Case Study of the Basque Country." American Economic Review 93(1): 113-132.

Abiad, A., Detragiache, E. and Tressel, T. (2008). "A New Database of Financial Reforms." IMF Working Paper WP/08/266.

Atkinson, A. B. and Piketty, T. (Eds.) (2007). Top Incomes Over The Twentieth Century: A Contrast Between Continental European and English-Speaking Countries. Oxford, Oxford University Press.

Atkinson, A. B. (2007). "Top Incomes in the United Kingdom over the Twentieth Century." in A. B. Atkinson, T. Piketty (Eds.) (2007) Top Incomes Over The Twentieth Century: A Contrast Between Continental European and English-Speaking Countries. Oxford, Oxford University Press.

Atkinson, A. B., and Piketty, T. (Eds.). (2010). Top Incomes: A Global Perspective, Oxford: Oxford University Press.

Atkinson, A. B., Piketty, T., Saez, E. (2011). "Top Incomes in the Long Run of History." Journal of Economic Literature 49(1): 3-71.

Banerjee, A. V., and Newman, A. F. (1993). "Occupational Choice and the Process of Development." Journal of Political Economy 101(2): 274-298.

Bebchuk, L. A., Fried, J. M., and Walker, D. I. (2002). "Managerial Power and Rent Extraction in the Design of Executive Compensation." The University of Chicago Law Review 69(3): 751-846.

Becher, D. A., Campbell II, T. L., and Frye, M. B. (2005). Incentive Compensation for Bank Directors: The Impact of Deregulation. The Journal of Business 78(5): $1753-1778$.

Beck, T., Demirgüç, A., and Levine, R. (2007). "Finance, Inequality and the Poor." Journal of Economic Growth 12(1): 27-49.

Beck, T., Demirgüç-Kunt, A., and Levine, R. (2010). "Financial Institutions and 
Markets Across Countries and Over Time: The Updated Financial Development and Structure Database." World Bank Economic Review 24(1): 77-92.

Beck, T., Levine, R., and Levkov, A. (2010). "Big Bad Banks? The Winners and Losers From Bank Deregulation in the United States." Journal of Finance 65(5): $1637-1667$.

Bellringer, C., and Michie, R. (2014). "Big Bang in the City of London: An Intentional Revolution or an Accident?" Financial History Review 21(02): 111-137.

Boustanifar, H., Grant, E. and Reshef, A. (2016), "Wages and Human Capital in Finance: International Evidence, 1970-2005." SSRN Working Paper .

Clarke, G. R., Xu, L. C., and Zou, H. F. (2006). "Finance and Income Inequality: What Do the Data Tell Us?" Southern Economic Journal 72(3): 578-596.

Clemons, E. K., and Weber, B. W. (1990). "London's Big Bang: A Case Study of Information Technology, Competitive Impact, and Organizational Change." Journal of Management Information Systems 6(4): 41-60.

Crawford, A. J., Ezzell, J. R. and Miles, J. A. (1995). "Bank CEO Pay-Performance Rrelations and the Effects of Deregulation." Journal of Business 68(2): 231-256.

Cuñat, V., and Guadalupe, M. (2009). "Executive Compensation and Competition in the Banking and Financial Sectors." Journal of Banking and Finance 33(3): 495-504.

Demirgüç-Kunt, A., and Levine, R. (2009). "Finance and Inequality: Theory and Evidence." Annual Review of Financial Economics 1(1): 287-318.

Galor, O., and Zeira, J. (1993). "Income Distribution and Macroeconomics." Review of Economic Studies 60(1): 35-52.

Gerardi, K. S., H. Rosen, and P. Willen (2010). "The impact of deregulation and financial innovation on consumers: The case of the mortgage market." Journal of Finance 65(1): 333-360.

Gibson, M. S. (2000). "Big Bang deregulation and Japanese corporate governance: A survey of the issues." in T. Hoshi, H. Patrick (Eds.) Crisis and Change in the Japanese Financial System, Springer US.

Girouard, N., and Blöndal, S. (2001). "House prices and economic activity." OECD Economics Department Working Papers No. 279.

Goolsbee, A. (2000). "What Happens When You Tax the Rich? Evidence from Executive Compensation." Journal of Political Economy 108(2): 352-378.

Gordon, R. H., Slemrod, J. B. (2000). "Are 'Real' Responses to Taxes Simply Income Shifting Between Corporate and Personal Tax Bases?" in J. B. Slemrod (Ed.), Does Atlas Shrug? The Economic Consequences of Taxing the Rich, Cambridge, MA: Harvard University Press. 
Greenwood, J., and Jovanovic, B. (1990). "Financial Development, Growth, and the Distribution of Income." Journal of Political Economy 98(5): 1076-1107.

Hubbard, R. G., and Palia, D. (1995). "Executive pay and performance evidence from the U.S. banking industry." Journal of Financial Economics 39(1): 105-130.

Jerzmanowski, M., and Nabar, M. (2013). "Financial Development and Wage Inequality: Theory and Evidence." Economic Inquiry 51(1): 211-234.

Kaplan, S. N., and Rauh, J. (2010). "Wall Street and Main Street: What contributes to the rise in the highest incomes?" Review of Financial Studies 23(3): 1004-1050.

Korpi, W., and Palme, J. (1998). "The paradox of redistribution and strategies of equality: Welfare state institutions, inequality, and poverty in the Western countries." American sociological review 63(5): 661-687.

La Porta, R., Lopez-de-Silanes, F., Shleifer, A., and Vishny, R. W. (1997). "Legal Determinants of External Finance." Journal of finance 52(3): 1131-1150.

Llewellyn, D. T. (1990). Competition, diversification and structural change in the British financial system." in D. E. Fair and C. de Boisseau (Eds.), Financial Institutions in Europe Under New Competitive Conditions, Dordrecht: Kluwer.

Lopez, J. A., and Spiegel, M. M. (2014). "Foreign Entry into Underwriting Services: Evidence from Japan's 'Big Bang' Deregulation." Journal of Money, Credit and Banking 46(2-3): 445-468.

Moriguchi, C., and Saez, E. (2008). "The Evolution of Income Concentration in Japan, 1886-2005: Evidence from Income Tax Statistics." Review of Economics and Statistics 90(4): 713-734.

Nickell, W. (2006). The CEP-OECD institutions data set (1960-2004). CEPDP, 759. Centre for Economic Performance, London School of Economics and Political Science, London, U.K.

Pagano, M., and Volpin, P. F. (2005). "The Political Economy of Corporate Governance." American Economic Review 95(4): 1005-1030.

Philippon, Thomas. 2015. "Has the US Finance Industry Become Less Efficient? On the Theory and Measurement of Financial Intermediation." American Economic Review 105(4): 1408-1438.

Philippon, T., and Reshef, A. (2012). "Wages and Human Capital in the US Finance Industry: 1909-2006." Quarterly Journal of Economics 127(4): 1551-1607.

Philippon, T., and Reshef, A. (2013). "An International Look at the Growth of Modern Finance." Journal of Economic Perspectives 27(2): 73-96.

Piketty, T., and Saez, E. (2007). "The evolution of top incomes: a historical and international perspectives." in Atkinson, A. B. (Ed.). Top incomes over the Twentieth 
Century: A Contrast between Continental European and English-Speaking Countries, Oxford: Oxford University Press.

Piketty, T., Saez, E., and Stantcheva, S. (2014). "Optimal Taxation of Top Incomes: A Tale of Three Elasticities." American Economic Journal: Economic Policy 6(1): 230-271.

Quinn, D. (1997). "The Correlates of Change in International Financial Regulation." American Political Science Review 91(3): 531-551.

Rajan, R. G., and Zingales, L. (2003). "The Great Reversals: The Politics of Financial Development in the Twentieth Century." Journal of Financial Economics 69(1): 5-50.

Roine, J., Vlachos, J., and Waldenström, D. (2009). "The Long-Run Determinants of Inequality: What Can We Learn from Top Income Data?" Journal of Public Economics 93(7): 974-988.

Roine, J. and Waldenström, D. (2012). "On the Role of Capital Gains in Swedish Income Inequality." Review of Income and Wealth 58(3): 569-587.

Saez, E., and Veall, M. R. (2005). "The Evolution of High Incomes in Northern America: Lessons from Canadian Evidence." American Economic Review 95(3): 831849.

Sherman, M. (2009). "A short history of financial deregulation in the United States." Center for Economic and Policy Research, 7.

Song, J., Price, D. J., Guvenen, F., Bloom, N., von Wachter, T. (2015). "Firming Up Inequality." Mimeo, Stanford University.

Takahashi, H. (2014). "The Effect of Bank-firm Relationships on Sell-side Research." Journal of Financial Services Research 46(2): 195-213.

Toya, T., and Amyx, J.A. (2006). The Political Economy of the Japanese Financial Big Bang: Institutional Change in Finance and Public Policymaking. New York: Oxford University Press.

Vlachos, J., and Waldenström, D. (2005). "International Financial Liberalization and Industry Growth." International Journal of Finance 65 Economics 10(3): 263-284.

Williams, J. (1988). "American Democratization Policy for Occupied Japan: Correcting the Revisionist Version." Pacific Historical Review 57(2): 179-202.

Williamson, J. and Mahar, M. (1998). "A Survey of Financial Liberalization." Essays in International Finance, Department of Economics of Princeton University, No. 211. 
Figure 1: Income decomposition of the Top $1 \%$

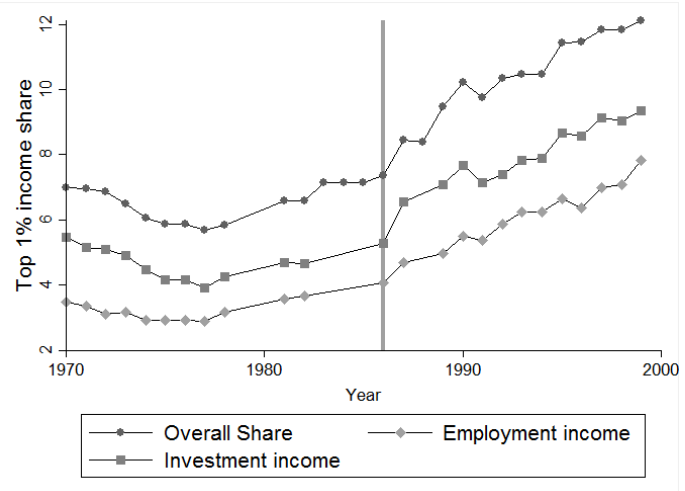

(a) United Kingdom source: Atkinson (2007)

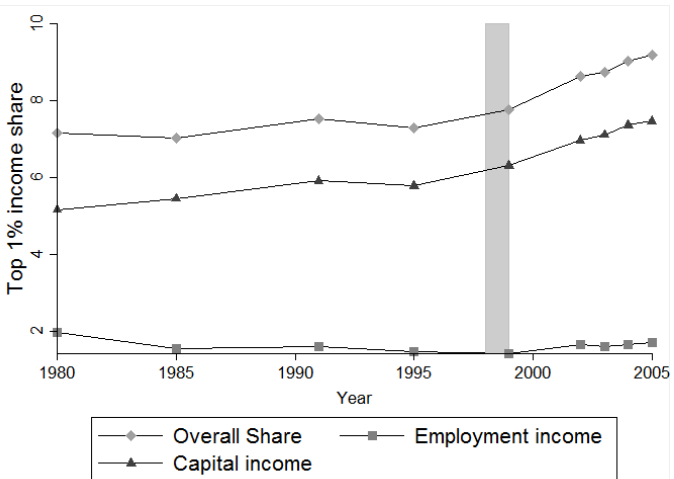

(b) The Japanese Top $1 \%$ income group source: Morichugi and Saez (2008) 
Table 1: Description of main control variables

\begin{tabular}{lll}
\hline Controls used & Description of variable & Source \\
\hline \hline $\begin{array}{l}\text { growth } \\
\text { GDPPCcons } \\
\text { rightwing }\end{array}$ & Annual GDP growth (\%) & WDI ** \\
& Right-wing executive & WDI ** \\
capital_quinn & Quinn index, & DPI, the World Bank. \\
& Keefer, 2012 \\
epl & Employment protection legislation & Quinn, 1997 \\
& (OECD data) & Nickell, 2006 \\
TopTaxRate & The highest marginal inocme tax rate & Piketty et al., 2014 \\
SMC_GDP & Stock market capitalization (\% of GDP) & Beck,Demirgüç-Kunt \\
& & and Levin, 2010 \\
ger_mom & Legal origin: Germany (used for Japan) & La Porta et al., 1997 \\
uk_mom & Legal origin: United Kingdom & La Porta et al., 1997
\end{tabular}

*Unemployment for France and U.K. complemented with national statistics data from INSEE and ONS.

** The World Bank (Updated: 2015-01-30) 
Table 2: Countries in synthetic control group, United Kingdom

\begin{tabular}{lrrrr}
\hline Outcome variables & Top $10 \%$ & Top $5 \%$ & Top $1 \%$ & Top 0.1\% \\
\hline \hline Australia & 0 & 0.144 & 0.396 & 0.545 \\
Canada & 0 & 0 & 0.394 & 0.435 \\
Denmark & 0 & 0 & 0 & 0 \\
Finland &. & 0 & 0 &. \\
France & 0 & 0 & 0 & 0 \\
Germany & 0 & 0 & 0 & 0 \\
Ireland & 0.689 & 0.21 & 0 \\
Italy & 0 & 0 & 0 & 0 \\
Japan & 0 & 0.513 & 0 & 0 \\
Netherlands & 0.311 & 0.343 & 0 & 0 \\
New Zealand & 0 & 0 & 0 &. \\
Norway & 0 & 0 & 0 & 0 \\
Sweden & 0 & 0 & 0 & 0.021 \\
Switzerland & 0 & 0 & 0 & 0 \\
\hline
\end{tabular}

Note: The synthetic control groups are composed of the weighted average of countries presented in the table. The weights are chosen as they represent best fit to each different top income trend and control variables prior to the treatment.

Table 3: Countries in synthetic control group, Japan

\begin{tabular}{lrrrr}
\hline Outcome variables & Top $10 \%$ & Top 5\% & Top 1\% & Top 0.1\% \\
\hline \hline Australia & 0 & 0.043 & 0 & 0 \\
Canada & 0 & 0 & 0 & 0.09 \\
Denmark & 0 & 0 & 0 & 0.682 \\
Finland &. & 0 & 0 &. \\
France & 0 & 0 & 0.661 & 0 \\
Ireland & 0 &. & 0 &. \\
Italy & 0 & 0 & 0 & 0 \\
Netherlands & 0 & 0.056 & 0.208 &. \\
New Zealand & 0 & 0 & 0 &. \\
Norway & 0 & 0.059 & 0 & 0 \\
Spain & 0.079 & 0.276 & 0.053 & 0.19 \\
Sweden & 0 & 0 & 0 & 0 \\
Switzerland & 0.599 & 0.439 & 0.078 & 0 \\
United States & 0.322 & 0.127 & 0 & 0.038 \\
\hline Nite: & $0.9 y$
\end{tabular}

Note: The synthetic control groups are composed of the weighted average of countries presented in the table. The weights are chosen as they represent best fit to each different top income trend and control variables prior to the treatment. 
Table 4: Comparison of control variables

\begin{tabular}{|c|c|c|c|c|c|c|}
\hline \multirow[t]{2}{*}{ Control variables } & \multirow[t]{2}{*}{ U.K. } & \multicolumn{4}{|c|}{ Synthetic control groups } & \multirow[t]{2}{*}{ Mean } \\
\hline & & Top $10 \%$ & Top $5 \%$ & Top 1\% & Top $0.1 \%$ & \\
\hline GDP growth & 2.24 & 3.32 & 3.47 & 3.37 & 3.21 & 2.58 \\
\hline GDP per capita & 21688 & 18948 & 21964 & 20543 & 22039 & 24805 \\
\hline Right-wing Executive & 0.63 & 0.64 & 0.82 & 0.40 & 0.36 & 0.4 \\
\hline British Legacy & 1 & 0.69 & 0.14 & 1 & 0.98 & 0.28 \\
\hline Employment protection & 0.19 & 0.47 & 0.71 & 0.28 & 0.29 & 0.72 \\
\hline Quinn index & 76.6 & 72.6 & 63.5 & 65.0 & 63.3 & 70.3 \\
\hline \multirow[t]{3}{*}{ Top Income Tax Rate } & 0.68 & 0.66 & 0.71 & 0.53 & 0.52 & 0.64 \\
\hline & Japan & \multicolumn{4}{|c|}{ Synthetic control groups } & Mean \\
\hline & & Top $10 \%$ & Top 5\% & Top $1 \%$ & Top $0.1 \%$ & \\
\hline GDP growth & 3.40 & 2.16 & 2.25 & 2.12 & 2.39 & 2.05 \\
\hline GDP per capita & 28608 & 39494 & 34788 & 28613 & 31906 & 32510 \\
\hline Right-wing Executive & 0.88 & 0.23 & 0.18 & 0.29 & 0.52 & 0.38 \\
\hline German legacy & 1 & 0.60 & 0.44 & 0.08 & 0 & 0.22 \\
\hline Employment protection & 0.70 & 0.31 & 0.60 & 0.90 & 0.74 & 0.78 \\
\hline Quinn index & 66.9 & 97.6 & 88.8 & 83.6 & 86.4 & 90.3 \\
\hline Top Income Tax Rate & 0.60 & 0.43 & 0.48 & 0.60 & 0.60 & 0.53 \\
\hline Stock Market Cap. & 82.9 & 87.3 & 69 & 43.6 & 35.1 & 51.3 \\
\hline
\end{tabular}

Note: Values of the control variables used to find the optimal synthetic control group in the pretreatment time period. For a good counterfactual, each synthetic control group should have control variable means close to the mean of the control variables for the treated country, compared to the mean in the donor pool (last column) The control variables are described in table 1. 
Figure 2: The British "Big Bang" in 1986
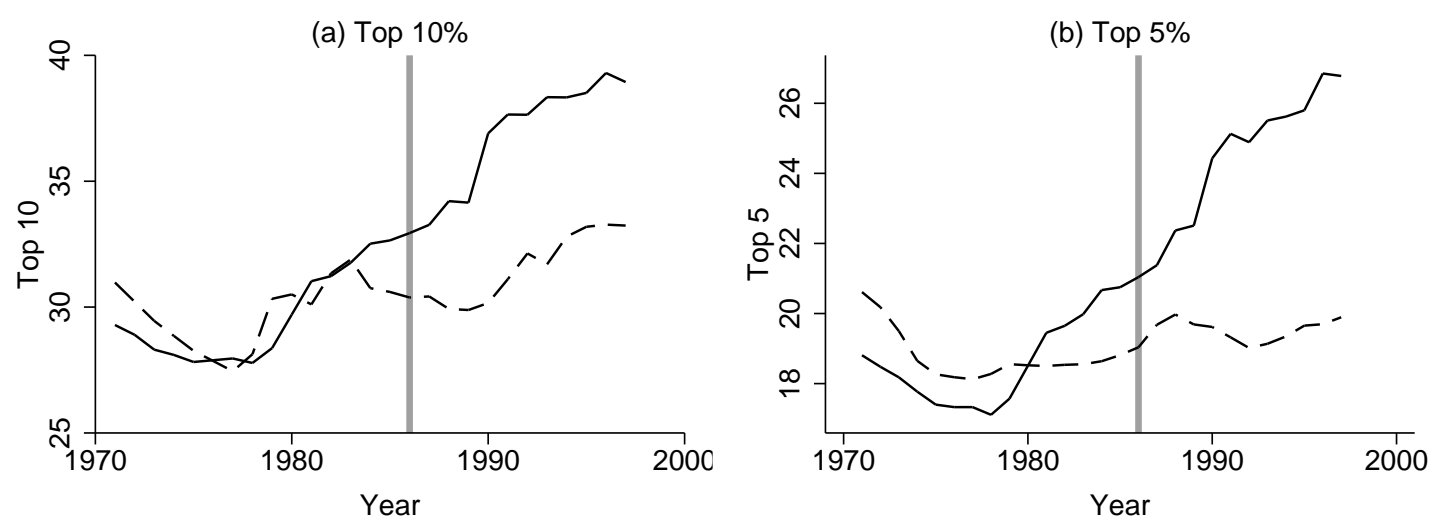

(c) Top 1\%
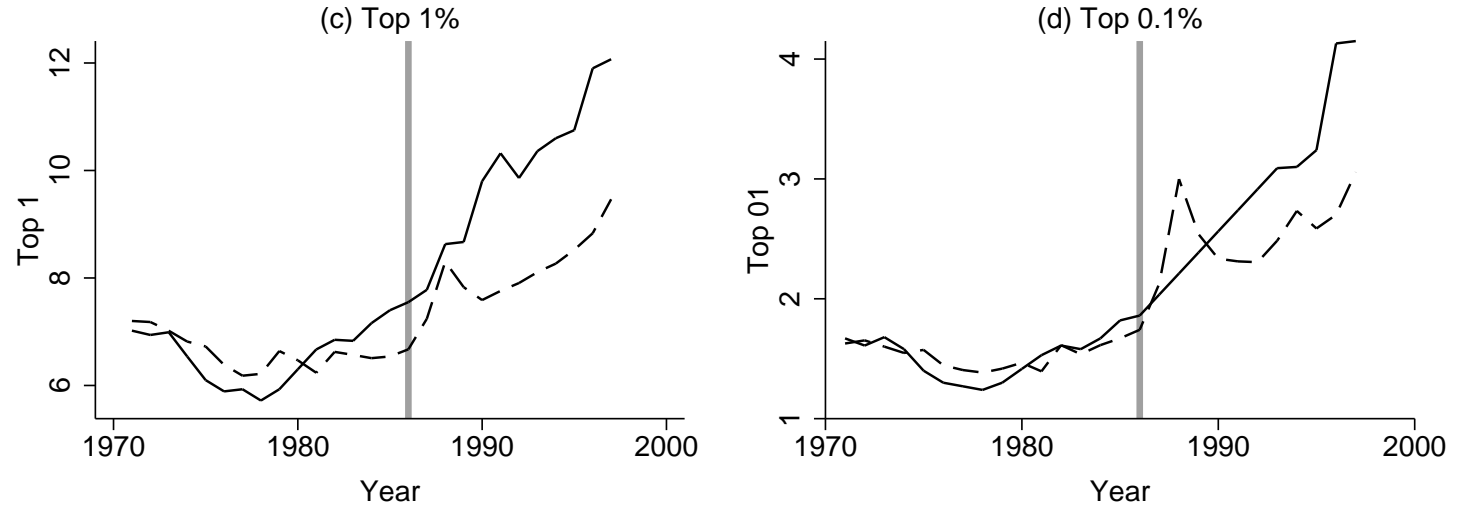

\section{United Kingdom $\quad----$ Synthetic United Kingdom}

Note: For each top income share, a synthetic control group (dashed line) is calibrated to match the true trend (solid line) prior to treatment. The trend of the synthetic control represents the trend in Japan in absence of the "big bang", and the difference between the two lines is the effect of financial deregulation on the top income share. 
Figure 3: Percentage Deviation from the Synthetic Control Group Trend, United Kingdom

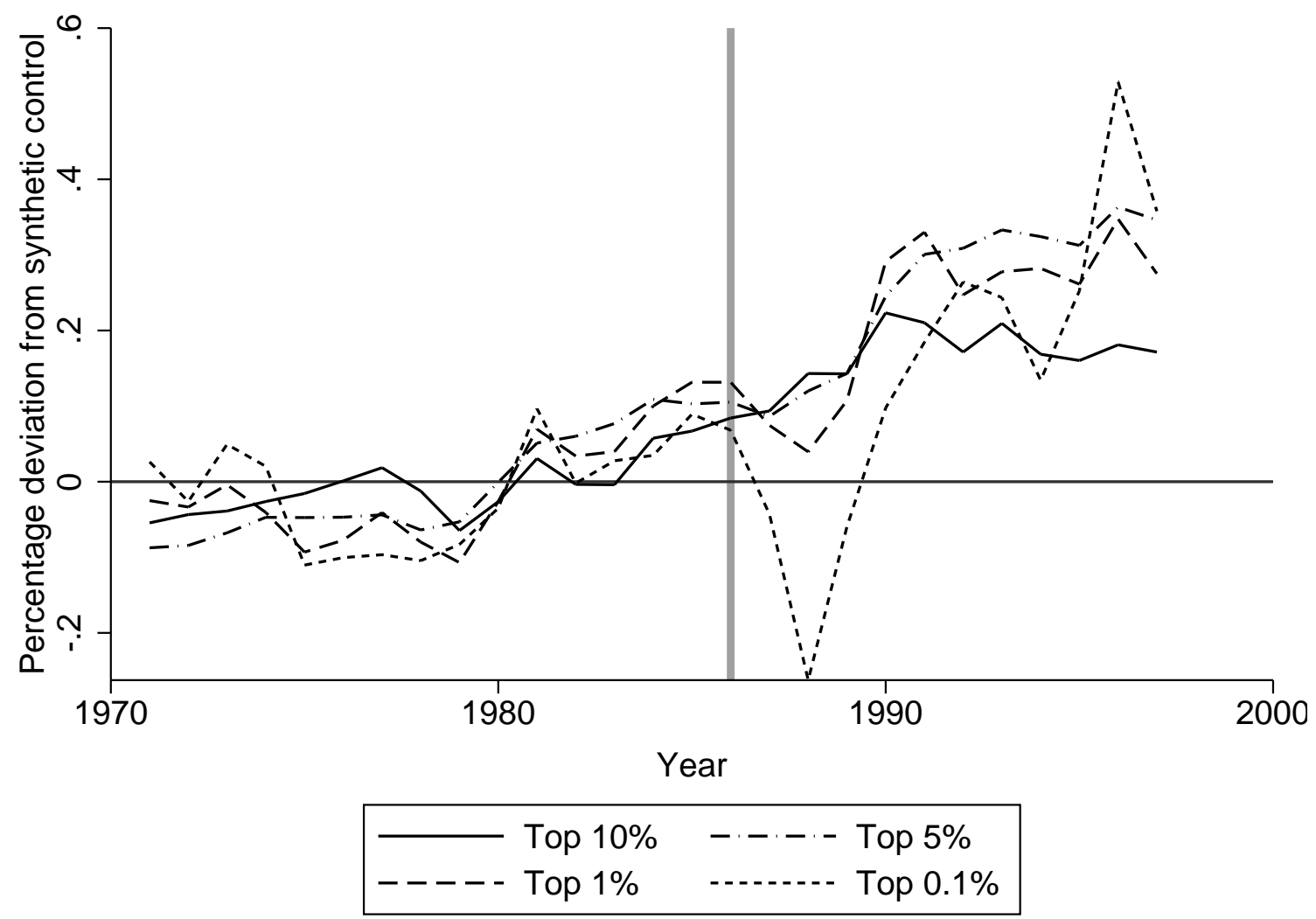

Note: Each line represent the percentage size of the gap between the real and the synthetic outcome in figure 2 . 
Figure 4: The Japanese Big Bang of 1997-1999
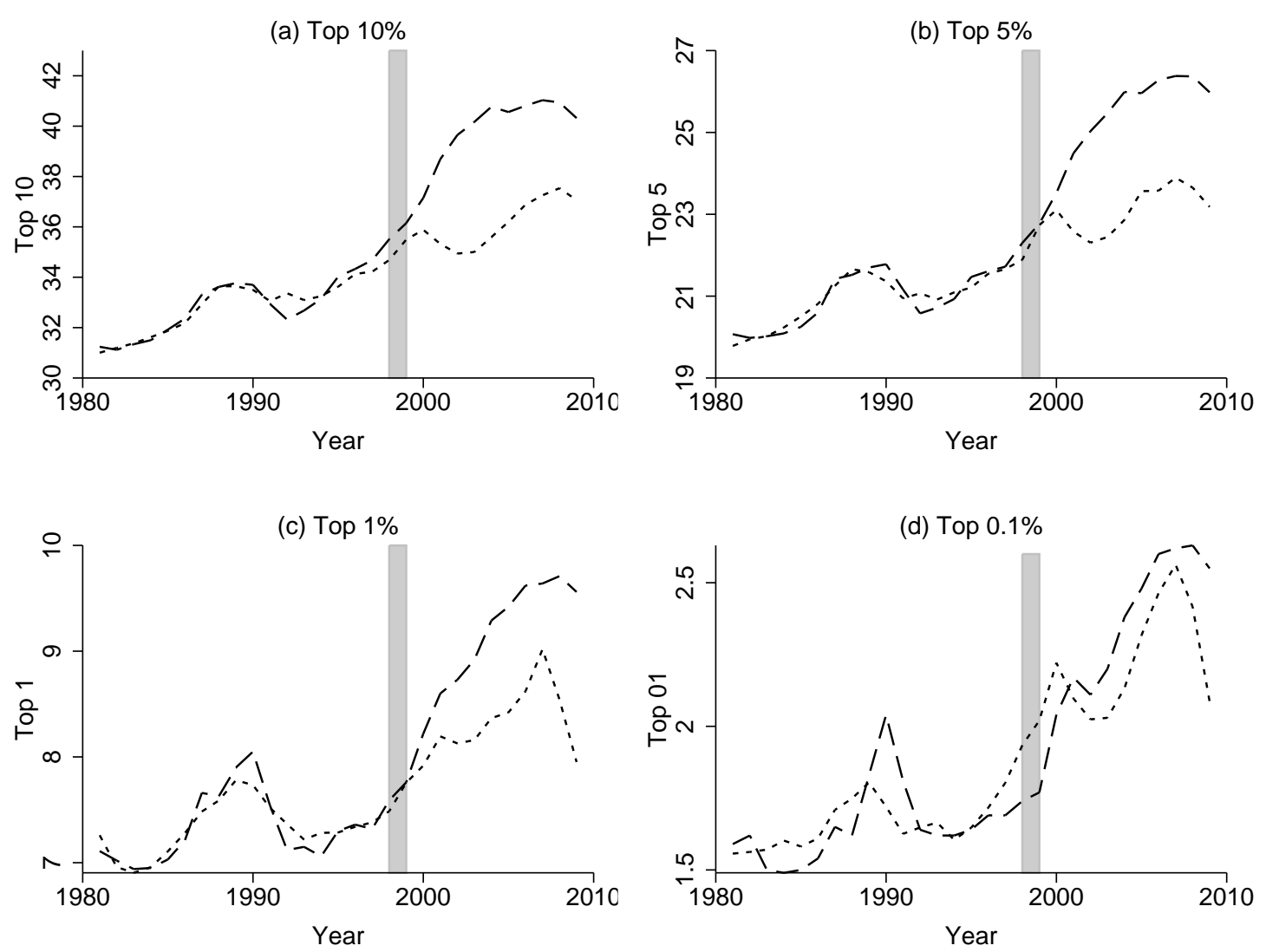

$$
\text { - - - Japan ........ Synthetic Japan }
$$

Note: For each top income share, a synthetic control group (dashed line) is calibrated to match the true trend (solid line) prior to treatment. The trend of the synthetic control represents the trend in Japan in absence of the "big bang", and the difference between the two lines is the effect of financial deregulation on the top income share. 
Figure 5: Percentage Deviation from the Synthetic Control Group Trend, Japan

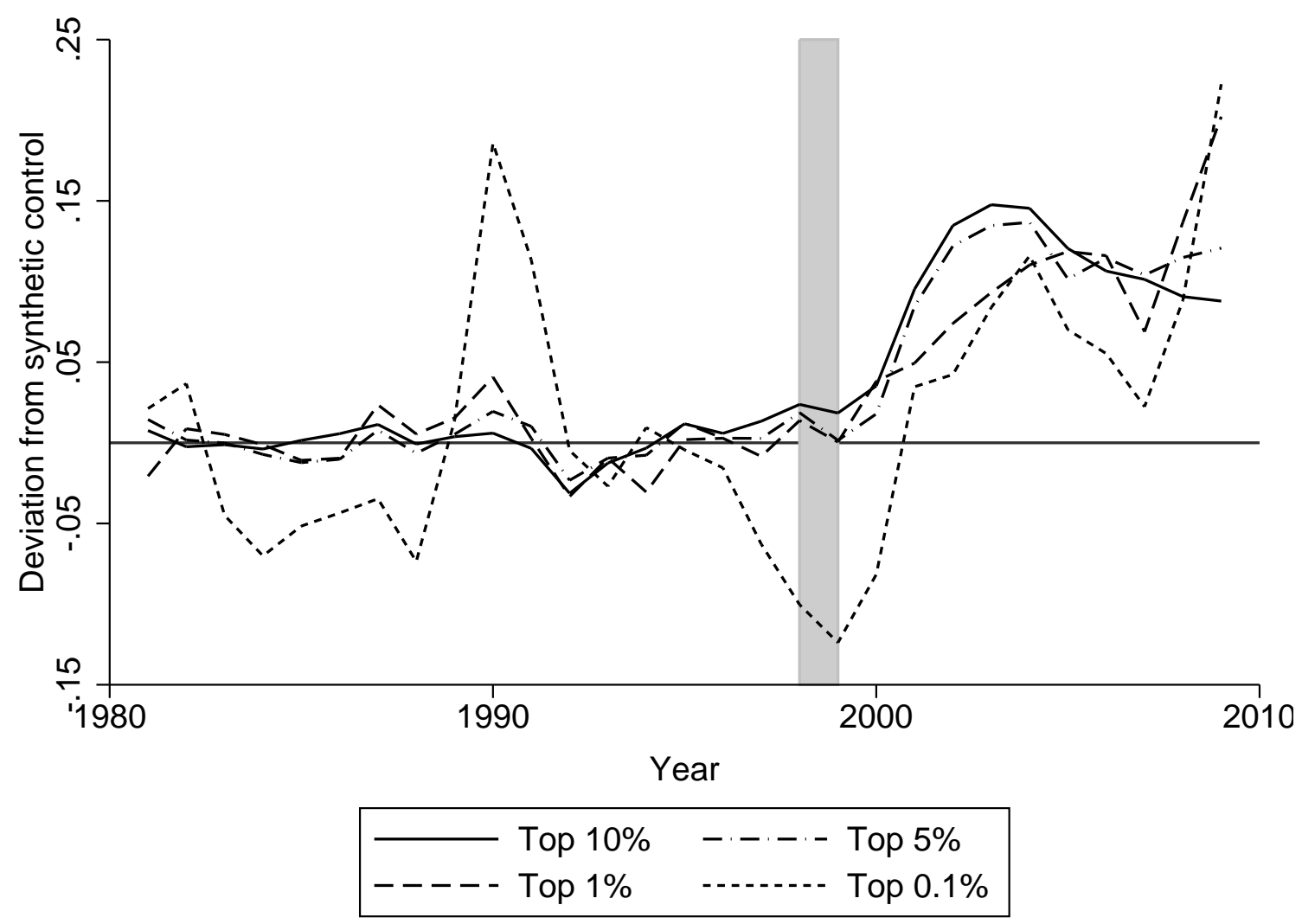

Note: Each line represent the percentage size of the gap between the real and the synthetic outcome in figure 4. 
Figure 6: Intermediate Shares
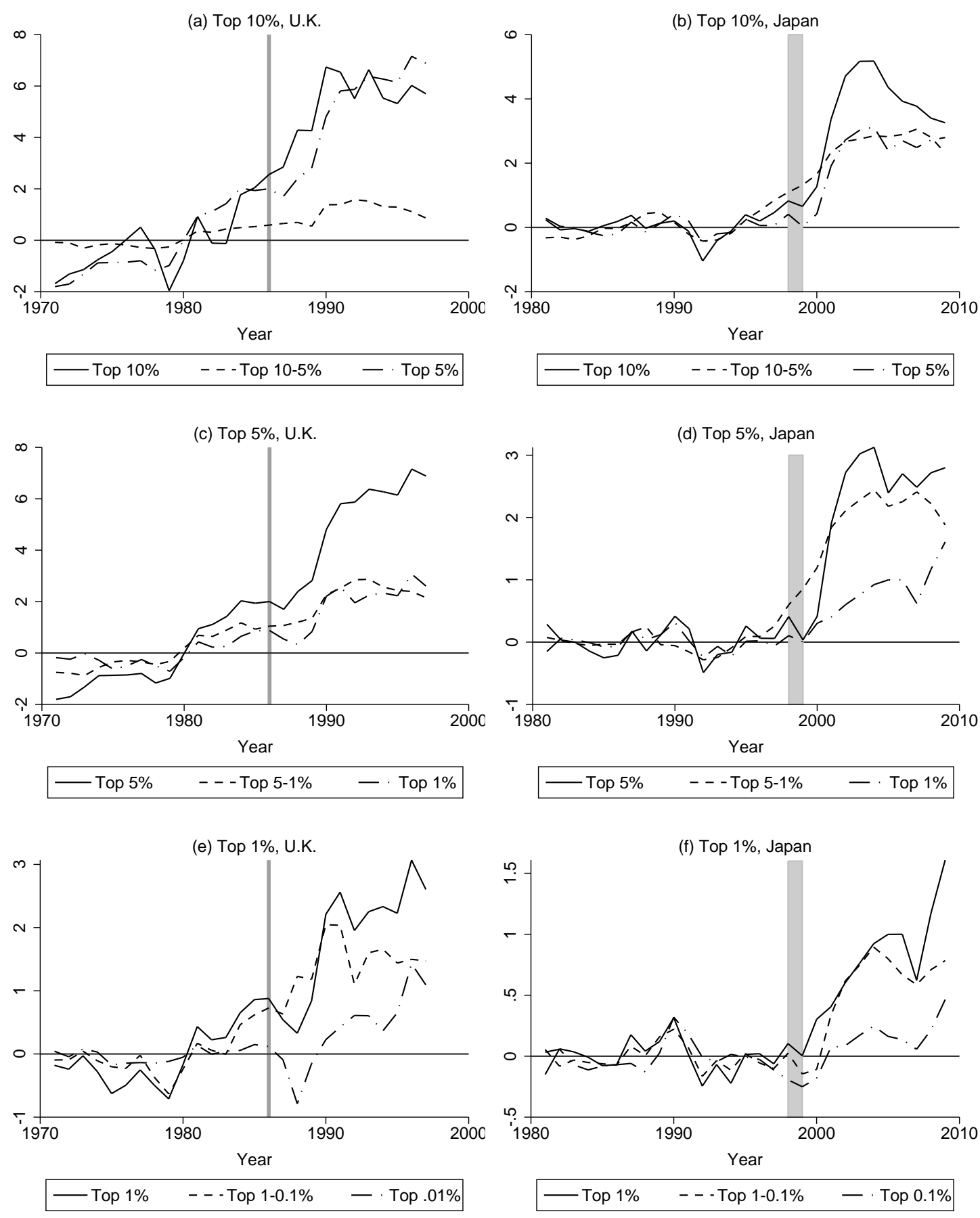

Note: Each line represent the real deviation from the synthetic control group. The "Top" shares are the same as in figures 2 and 4 , while the intermediate shares are. 
Figure 7: Placebo tests - United Kingdom
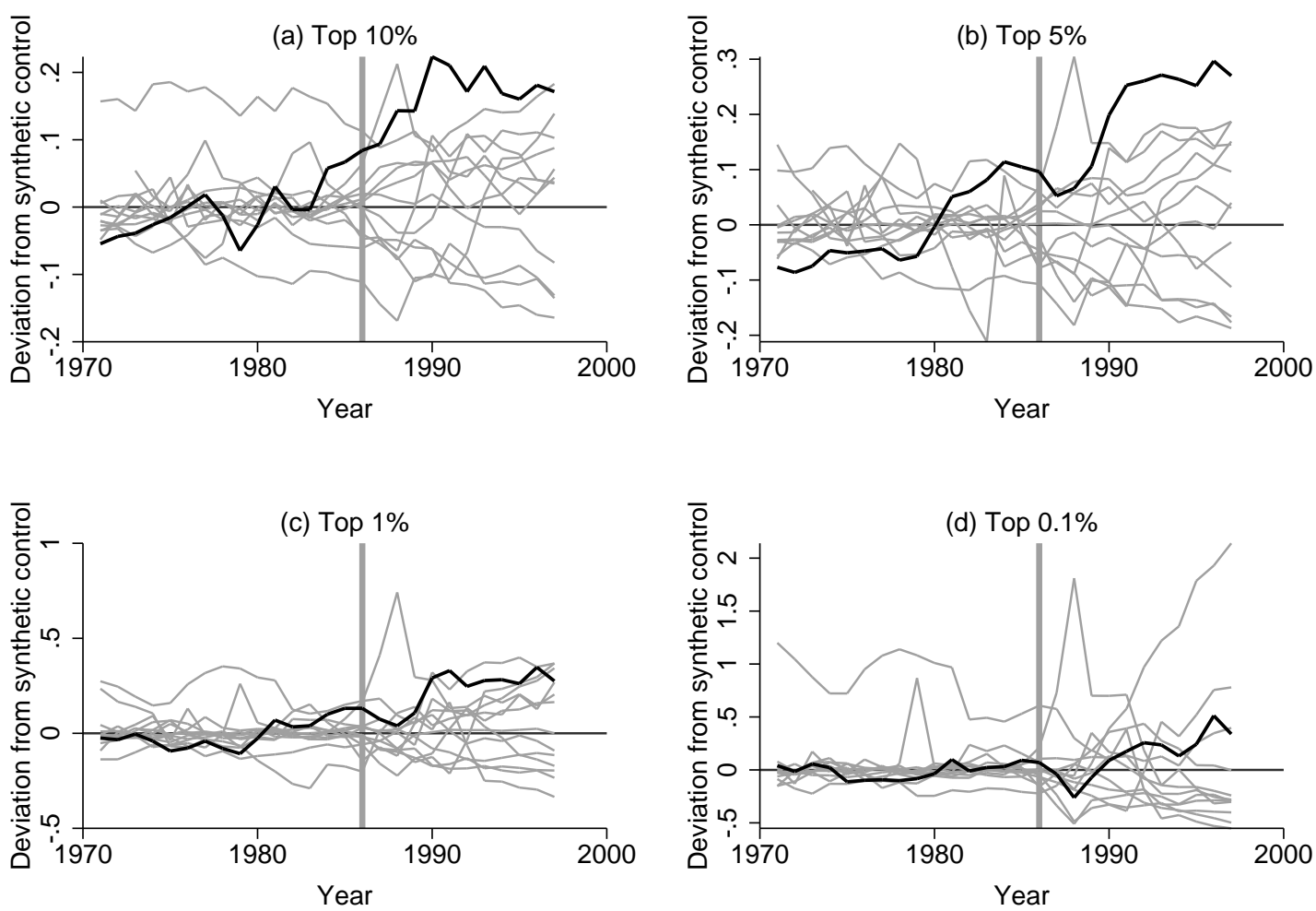

Note: The black solid line represent the percentage deviation of U.K./Japan from its baseline synthetic control group. Each of the grey lines represent a gap between the true outcome and the synthetic control group for every country in the donor pool (for which no deviations are expected). The donor pool consist of all countries with 0 or positive weight in table 2 and 3. 

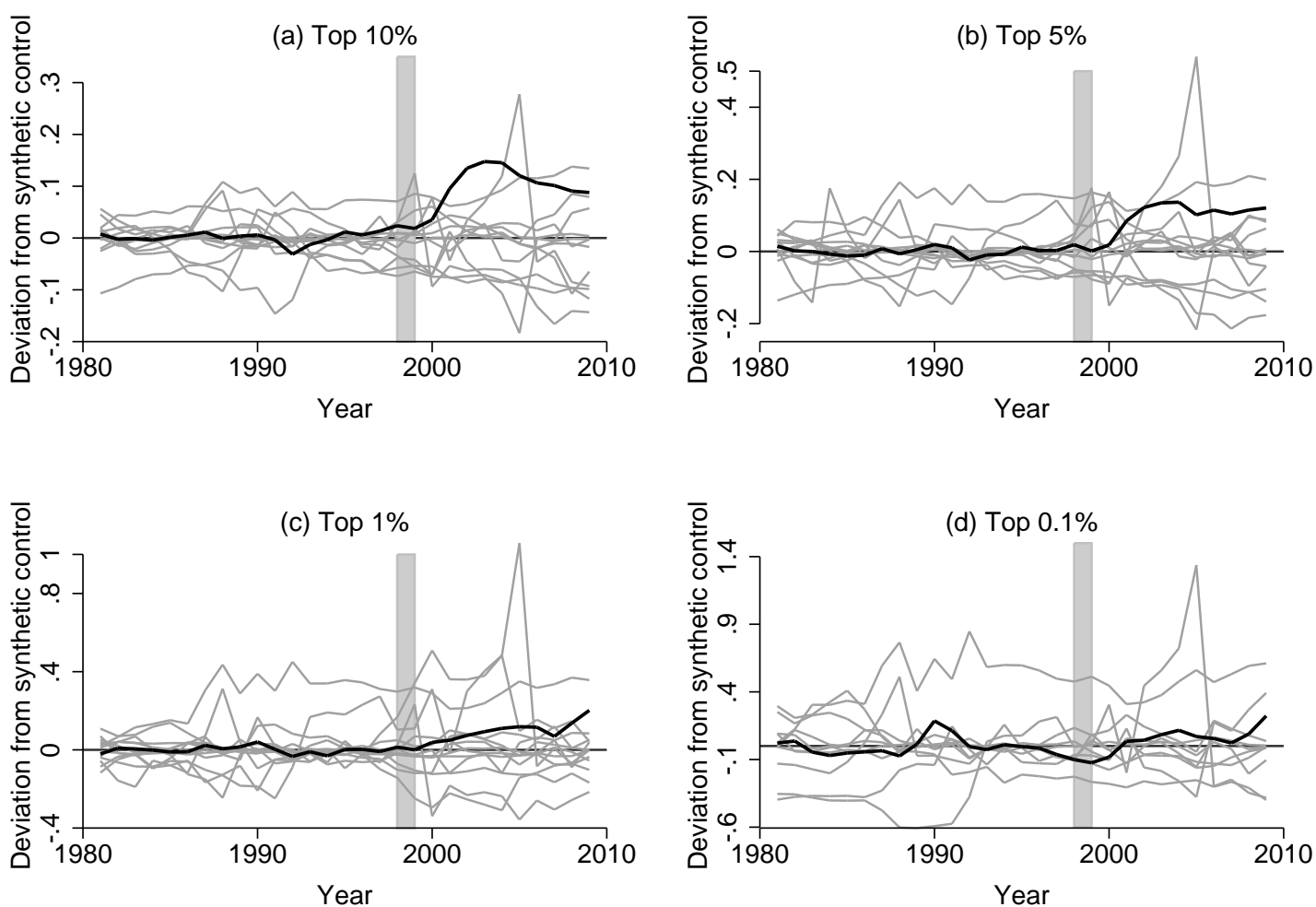

Note: The black solid line represent the percentage deviation of U.K./Japan from its baseline synthetic control group. Each of the grey lines represent a gap between the true outcome and the synthetic control group for every country in the donor pool (for which no deviations are expected). The donor pool consist of all countries with 0 or positive weight in table 2 and 3. 
Table 5: Significance of the Synthetic Control Group estimations according to placebo tests

\begin{tabular}{lllll|llllll}
\hline \multicolumn{1}{c}{ United Kingdom } \\
\hline \hline Year & Top 10 & Top 5 & Top 1 & Top 0.1 & Year & Top 10 & Top 5 & Top 1 & Top 0.1 \\
\hline 1986 & .083 & 0 & .154 & .33 & 1997 & .167 & .33 & .417 & .44 \\
1987 & .083 & .25 & .154 & .5 & 1998 & .167 & .417 & .417 & .33 \\
1988 & .083 & .167 & .23 & .83 & 1999 & .25 & .583 & .615 & .56 \\
1989 & 0 & .083 & .154 & .67 & 2000 & .25 & .417 & .23 & .33 \\
1990 & 0 & 0 & .077 & .583 & 2001 & 0 & .167 & .31 & .44 \\
1991 & 0 & 0 & 0 & .33 & 2002 & 0 & .083 & .384 & .33 \\
1992 & 0 & 0 & .077 & .167 & 2003 & 0 & .083 & .23 & .22 \\
1993 & 0 & 0 & .077 & .25 & 2004 & 0 & .167 & .23 & .22 \\
1994 & 0 & 0 & .077 & .25 & 2005 & .167 & .167 & .154 & .22 \\
1995 & 0 & 0 & .154 & .25 & 2006 & .083 & .083 & .31 & .33 \\
1996 & 0 & 0 & 0 & .167 & 2007 & .083 & .083 & .384 & .11 \\
1997 & .083 & 0 & .23 & .25 & 2008 & .083 & .167 & .154 & .22 \\
& & & & & 2009 & .083 & .083 & .077 & .22 \\
\hline
\end{tabular}

Note: This table shows, for each year, the probability of getting a more extreme positive deviation from the synthetic control group than the deviation for the true treatment country. It relates to the graphs in figures 7 and 8, as the number represents the share of grey lines that are higher than the black line for each year. The population consist of the donor pool population for each top income share (all countries with 0 or positive weight in table 2 and 3 ). 
Figure 9: Test of control variables - United Kingdom
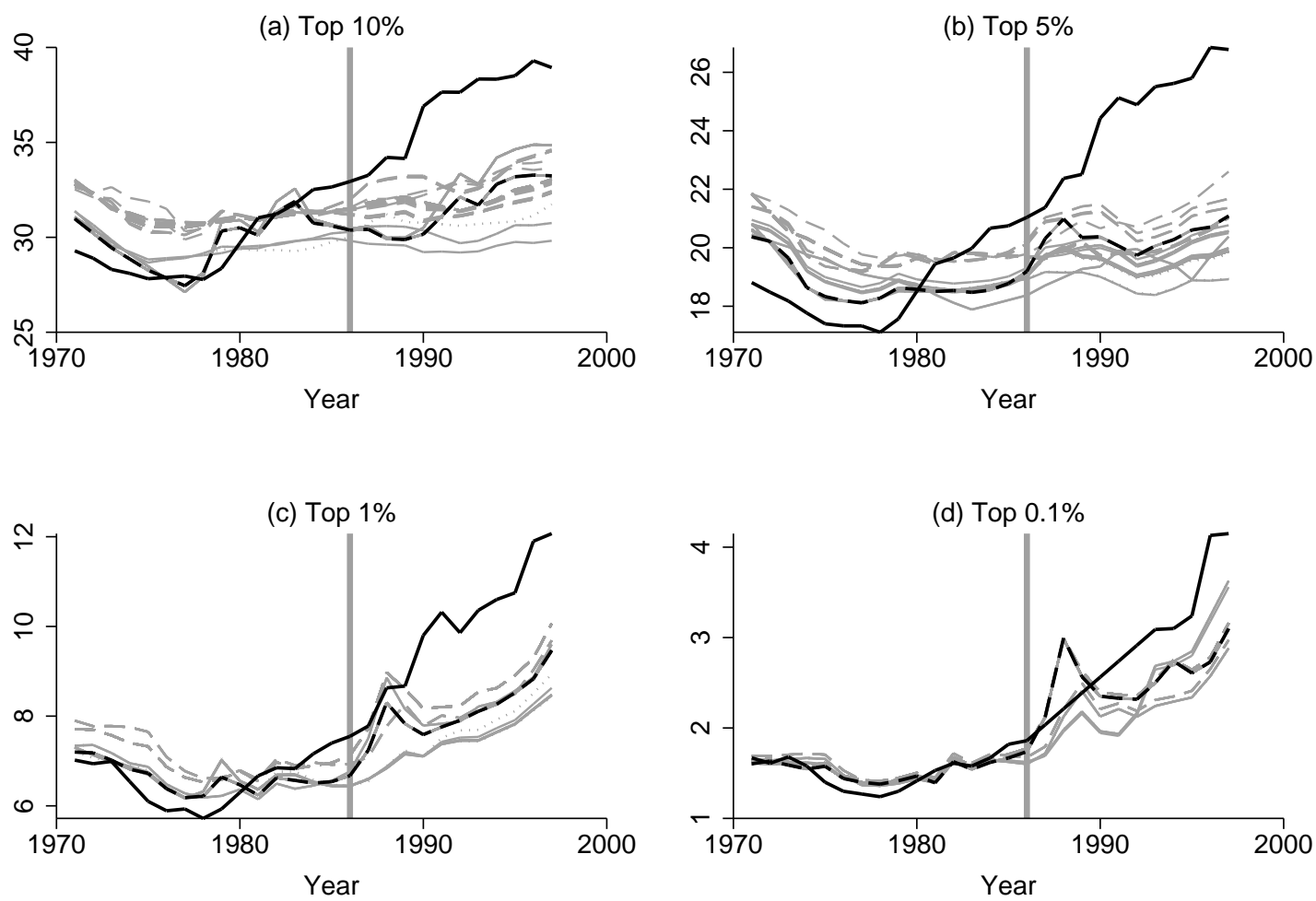

Note: The black solid line is the true U.K./Japanese trend. The black dashed line is the synthetic control group trend calculated from the baseline set of control variables, and each grey line represent the synthetic control group obtained with a different set of controls. Each combination of controls tested is presented in appendix table A3 and the controls are described in appendix table A2. The different patterns for the grey lines (solid, dashed of dotted) indicate a different set of years are used in the optimisation. The years are listed in appendix table A4. 
Figure 10: Test of control variables - Japan

(a) Top 10\%

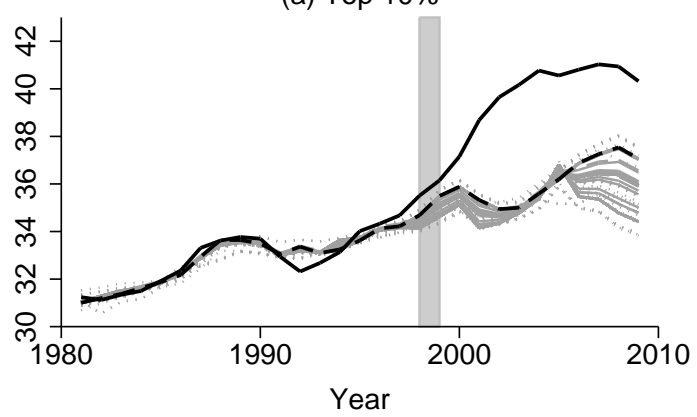

(c) Top $1 \%$

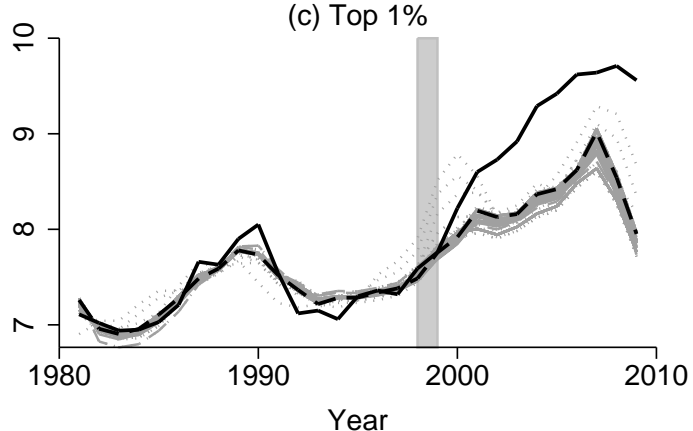

(b) Top 5\%

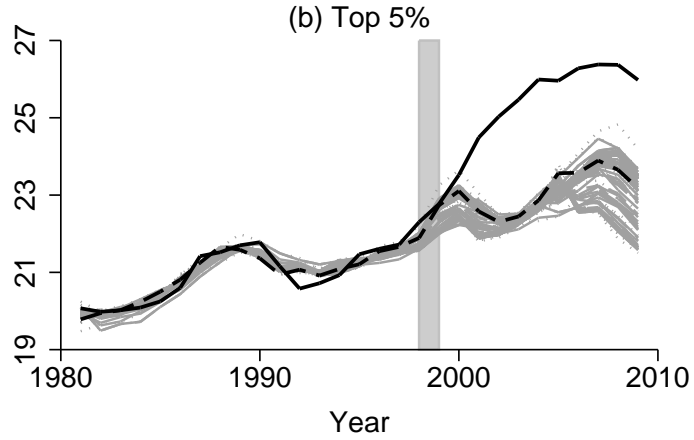

(d) Top $0.1 \%$

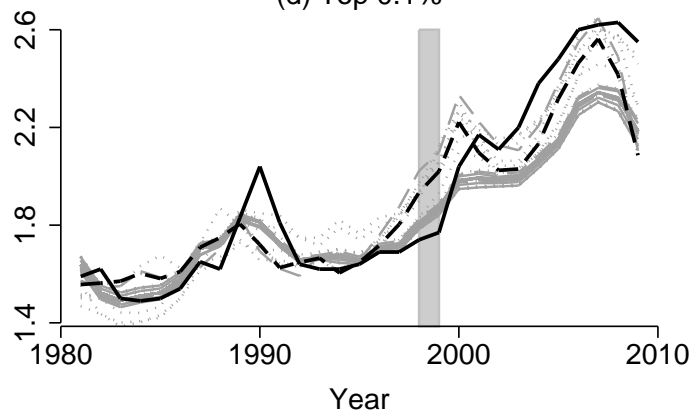

Note: The black solid line is the true U.K./Japanese trend. The black dashed line is the synthetic control group trend calculated from the baseline set of control variables, and each grey line represent the synthetic control group obtained with a different set of controls. Each combination of controls tested is presented in appendix table A3 and the controls are described in appendix table A2. The different patterns for the grey lines (solid, dashed of dotted) indicate a different set of years are used in the optimisation. The years are listed in appendix table A4. 
Figure 11: Post-treatment trends in control variables, U.K.

\section{United Kingdom}
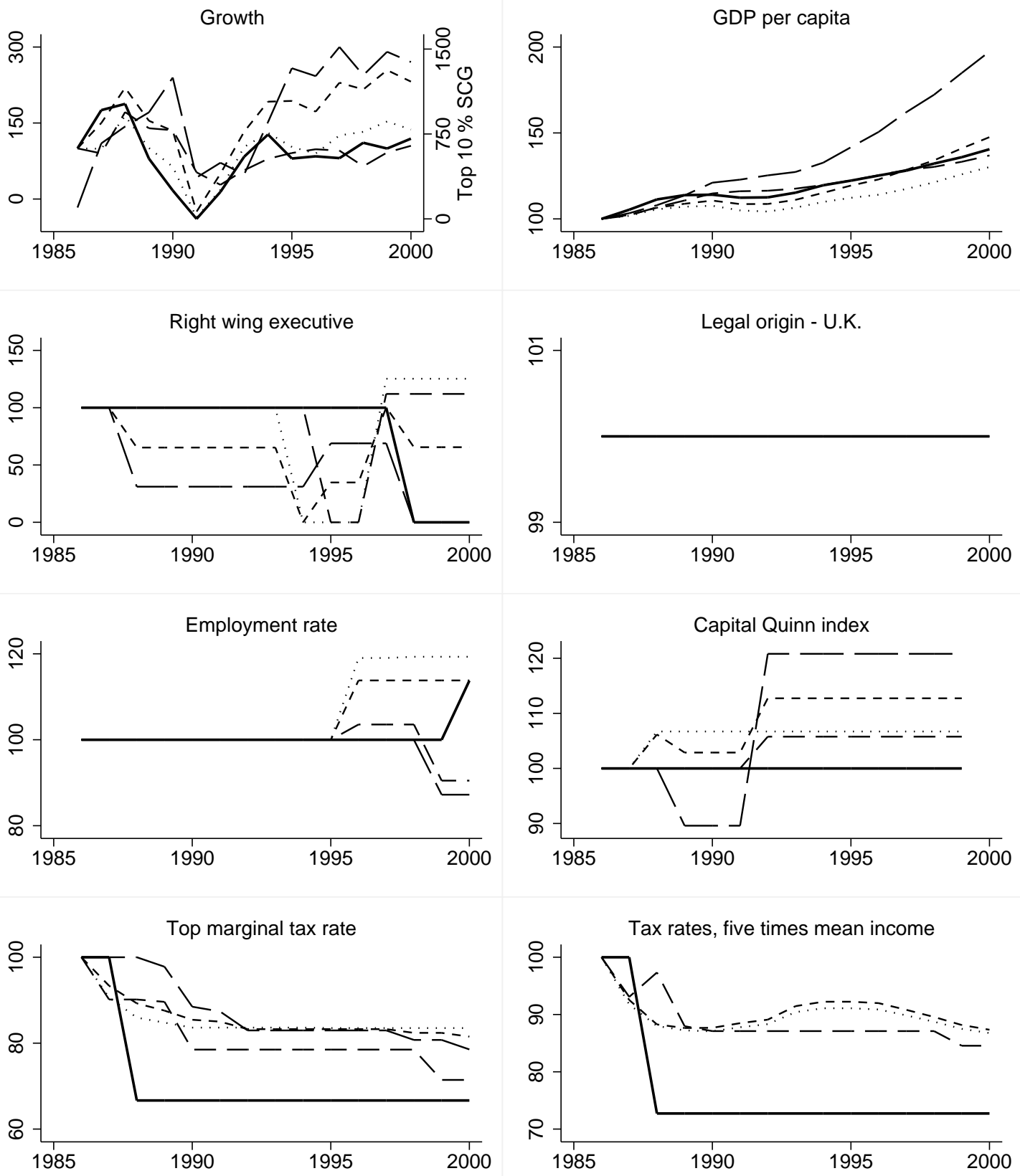

- Synthetic Control Group, Top 10\%

- Synthetic Control Group, Top 5\%

- - Synthetic Control Group, Top 1\% Synthetic Control Group, Top $0.1 \%$

- United Kingdom 
Figure 12: Post-treatment trends in control variables, Japan

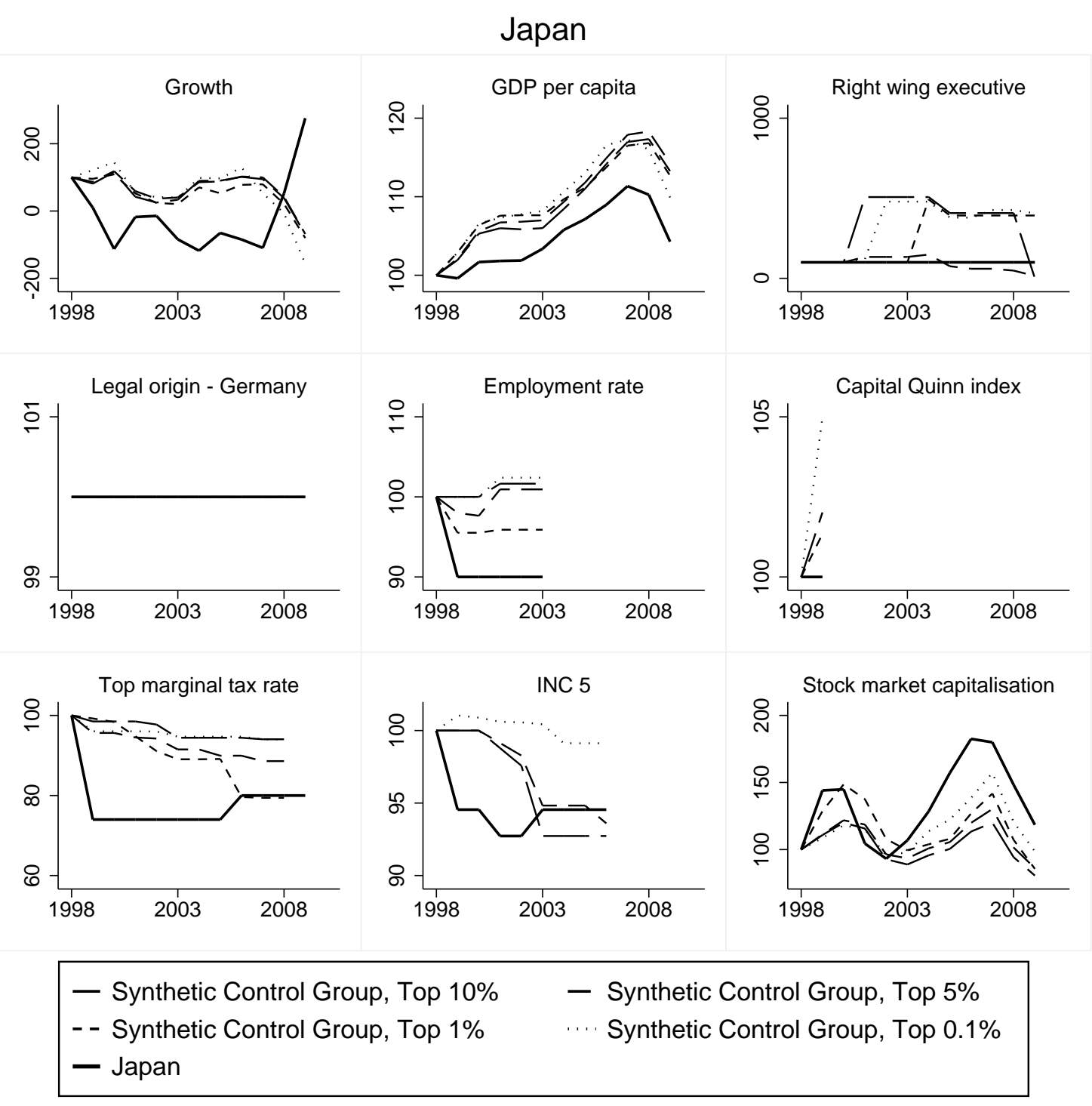




\section{A Data Appendix}

\section{A.1 Top Income Data}

All data on top income shares are from the World Wealth and Income Database (WID). The following table describes the differences between the top income measures for each country, and if there have been any changes made to the data before its use in the donor pool.

The table is constructed as follows: Specific information about the data for each country in WID is summarized in column one, in order to explain why he donor pool differs for the SCG for the U.K. and Japan respectively, and also to highlight differences in measurement between the countries with respect to tax units and age groups. The next two columns indicate if the country is in the donor pool. Yes means it is included in all top income groups, and no means it is excluded in all groups. Countries excluded from both donor pools are not in this table. Please see the WID for more info about these countries.

In the fourth column, any adjustments to the data (interpolations) made by the authors before using the series is explained. Since the synthetic control method program as created by Abadie et. al. (2011) is unable to handle non-balanced panels or empty values in a series, interpolation becomes necessary.

The last column shows the treatment of realized capital gains in the baseline donor pools. An attempt is made to test the effect of realized capital gains in the robustness and mechanism analysis.

The tax units are either individuals or families, depending on tax legislation of the country. There is no difference in trends between the two methods, but there may be a difference in the level of the top income share (Atkinson et al., 2009). Hence, this might cause problems if the tax units change during the time period studied. Any breaks in the treatment of tax units is stated in column one. 
Table A1: Characteristics of international top income data

\begin{tabular}{|c|c|c|c|c|c|}
\hline Country & Country specific information & $\begin{array}{l}\text { In donor por } \\
\text { U.K. }\end{array}$ & ol Jap & Changes to original data & Capital Gains \\
\hline Australia & Capital income included when taxble under income tax (Atkinson et al, 2009) & $\mathrm{Y}$ & $\mathrm{Y}$ & No & Included \\
\hline Canada & $\begin{array}{l}\text { The U.K. donor pool use data from Saez and Veall (2005), which goes up to year } 2000 \text {. } \\
\text { The series is based on tabulated tax data, and relate to adults aged } 20+\text {. } \\
\text { The Japanese donor pool includes a newer series, which is available from 1982-2010, } \\
\text { but this is not included in the baseline data in order to avoid a break } \\
\text { in the method of estimation close to the time of treatment. }\end{array}$ & $\mathrm{Y}$ & $\begin{array}{l}\text { Y } \\
\text { for U.K. and Japan }\end{array}$ & $\begin{array}{l}\text { Different series } \\
\text { Constant start for } \\
\text { Japanese data: } 1981=1982\end{array}$ & Excluded \\
\hline Denmark & $\begin{array}{l}\text { Tax units are individuals over age } 15 \text {. Interpolated (linearly) for missing years: } \\
\text { Top1: } 1973 \text {, Top 0.1: } 1971,1973 \text { and } 1976 .\end{array}$ & $\mathrm{Y}$ & $\mathrm{Y}$ & Interpolated & Excluded \\
\hline Finland & $\begin{array}{l}\text { For Top } 10 \% \text { and Top } 0.1 \% \text { income share data only available from } 1990 . \\
\text { Break in series 1990, when data shift from tax data so survey data. }\end{array}$ & $\begin{array}{l}\text { Top } 5 \% \\
\text { Top } 1 \%\end{array}$ & $\begin{array}{l}\text { Top } 5 \% \\
\text { Top } 1 \%\end{array}$ & No. & \\
\hline France & Tax unit - Family. & $\mathrm{Y}$ & $\mathrm{Y}$ & No. & Excluded \\
\hline Germany & $\begin{array}{l}\text { West Germany prior to } 1990 \text {, with families as tax units. There is no data after } 1998 \text {, } \\
\text { why Germany is excluded from Japan's donor pool. Data available every third year. }\end{array}$ & $\mathrm{Y}$ & No & $\begin{array}{l}\text { Linear interpolation from } \\
\text { triannual data: } 1971-1998\end{array}$ & Excluded \\
\hline Ireland & $\begin{array}{l}\text { Data exist for top } 10 \text { and } 1 \% \text { from } 1975 \\
\text { Tax unit - Family. The Top } 0.1 \% \text { data ends in } 1991 \text {, and there is no data for Top } 5 .\end{array}$ & Top $10 \%$ & Top $10 \%$ & $\begin{array}{l}\text { Constant level of top } \\
\text { incomes } 1971-1975\end{array}$ & Excluded \\
\hline Italy & $\begin{array}{l}\text { Tax unit - individuals } \\
\text { No data prior to } 1974 \text {, a constant level is assumed 1971-74 for U.K. }\end{array}$ & $\mathrm{Y}$ & $\mathrm{Y}$ & Interpolated 1996-1997. & Excluded \\
\hline Japan & Tax unit - Individual. Series exist both including and excluding capital gains. & $\mathrm{Y}$ & & No. & Excluded \\
\hline Netherlands & $\begin{array}{l}\text { Tax unit - Family. } \\
\text { Data every second or every fourth year } 1970-1989 \text {. } \\
\text { No data post } 2000 \text { for the Top } 0.1 \%\end{array}$ & $\mathrm{Y}$ & $\begin{array}{l}\text { Top } 10 \% \\
\text { Top } 5 \% \\
\text { Top } 1 \%\end{array}$ & Interpolated 1971-1988. & Excluded \\
\hline New Zealand & $\begin{array}{l}\text { Tax unit - individuals } \\
\text { No data on top } 0.1 \% \text { after } 1990 .\end{array}$ & $\begin{array}{l}\text { Top } 10 \% \\
\text { Top } 5 \% \\
\text { Top } 1 \%\end{array}$ & $\begin{array}{l}\text { Top } 10 \% \\
\text { Top } 5 \% \\
\text { Top } 1 \%\end{array}$ & No. & $\begin{array}{l}\text { Included } \\
\text { where taxable }\end{array}$ \\
\hline Norway & Tax unit - individuals used in calculations. & $\mathrm{Y}$ & $\mathrm{Y}$ & No. & Included \\
\hline $\begin{array}{l}\text { Spain } \\
\text { Sweden }\end{array}$ & $\begin{array}{l}\text { Tax unit - individuals. Only one data point between 1961-1981 } \\
\text { Tax unit - individuals }\end{array}$ & $\begin{array}{l}\text { No } \\
\text { Y }\end{array}$ & $\begin{array}{l}\mathrm{Y} \\
\mathrm{Y}\end{array}$ & $\begin{array}{l}\text { No. } \\
\text { No. }\end{array}$ & $\begin{array}{l}\text { Excluded } \\
\text { Excluded }\end{array}$ \\
\hline Switzerland & $\begin{array}{l}\text { Tax unit - Family. Biannually 1943-1995. } \\
\text { Differences in taxation unit change } 95-96 \text { and a different data source from } 1995 .\end{array}$ & $\mathrm{Y}$ & $\mathrm{Y}$ & Interpolated 1971-1995. & Excluded \\
\hline United Kingdom & $\begin{array}{l}1980 \text { Missing Change in unit of taxation (from family to individuals) at } 1990 . \\
\text { For the Top } 0.1 \% \text {, Data is missing in the entire period from } 1987-1992 \\
\text { For these years, the time series is interpolated. }\end{array}$ & & $\mathrm{N}$ & Top 0.1 Interpolated 1987-1992. & $\begin{array}{l}\text { Included } \\
\text { where taxable }\end{array}$ \\
\hline United States & $\begin{array}{l}\text { Tax unit - Family } \\
\text { The Tax Reform act of } 1986 \text { changed rules regarding deductions etc. } \\
\text { which increased the reported top income shares. } \\
\text { Since this occurred the same year as the U.K. big bang, } \\
\text { the US is excluded from the donor pool, not to confuse effects. }\end{array}$ & No & $\mathrm{Y}$ & No. & Excluded \\
\hline
\end{tabular}




\section{A.2 Control Variables}

There is no consensus in the literature regarding exactly which exogenous factors are the most important to explain of top incomes, neither which indicators should be used to proxy for broader concepts such as political institutions. These explanatory variables correspond to the $\mathrm{Z}$ vector of control variables in $\mathrm{ADH}$ 's framework.

It is econometrically impossible to control for all possible variables (due to over-fitting), so our approach has been to test the robustness of our preferred choice of control variables. The result of this test is shown in the Robustness analysis section (robustness of control variable selection) and here follows a closer description of the alternative control variables and the compositions in the robustness tests.

The aim is to show graphically that the results are not driven by how $\mathrm{Z}$ is defined or which years are chosen to pin down the previous trend in Y. The test involves 21 different variables in 40 combinations, and each combination is matched with three different sets of years which the SCG will be pinned against. This gives 120 regressions, one of which is the original. The other 39 combinations are not strict randomly chosen, some consideration have been taken to the plausibility of the combination, comparing the original to "similar" sets of controls.

The baseline set of control variables that is used in the study is described in the Data section $^{25}$, and the additional controls in the robustness tests are presented in table A2. The alternative controls are aiming to capture the country's tax system, economic development, trade, political institutions, financial openness and technological development.

The last category is an aspect that may be important for the big bang in U.K. that is not discussed in the data section. Since the computerization of the stock exchange was also a part of the big bang (see section 2.2.1) technology may have impacted the likelihood of the big bang occurring. The CHAT database (Comin and Hobijin, 2009) has been consulted to find a good measure of computerization in the financial sector. The CHAT database tracks the amount of technological tools used in a country for a number of different technologies, from agricultural machines to internet usage. Unfortunately, there is no measure of computers used in business in this database, and the level of personal computer usage data begin in the ' 80 s, unfortunately after 1986 for most of the countries in the donor pool which makes it impossible to use as a control. In the alternative specification of controls, the proxy variable "number of cell phones" has been used, but the relevance of this can be questioned.

In table A3 each column represents a combination of controls used in the robustness test. An $\mathrm{x}$ indicate these variables are included in both the U.K. and Japan tests, while a $\mathrm{U}$ or $\mathrm{J}$ mean only the respective country included that variable.

Each of these 40 control combinations are used in the optimization function along with three different sets of years for the pre-treatment level of the top income share in question. The years are presented in table A4. The second version for the U.K. is

\footnotetext{
${ }^{25}$ They are: GDP growth, GDP per capita, Right-wing executive, legal origin (British or German) Employment protection, Financial openness in terms of the Quinn index and Top income tax rates.
} 
referred to as the "Thatcher era" in the paper.

\section{A.3 Variables determining the timing of financial deregulation}

There is a central issue of endogeneity when studying how policy decisions affect economic outcomes: What if it was the economic prerequisites that caused the change in the first place? What if there is some underlying variable that could have caused both the increase in top income shares and the financial deregulation?

To some extent, the synthetic control group can control for this. By taking parameters that may have affected the likelihood of a financial deregulation as well as the income distribution into account when choosing the control group, the counterfactual should ideally have the same probability of an unexpected increase in the relevant top income share as well as of a "big bang", if factors relevant to both of these outcomes are matched by the synthetic control. It is however hard to find such an ideal synthetic control, and the more controls are included, the less weight will be put on each of the variables. Therefore, the controls must be chosen with care, and take into account both the income distribution and the likelihood of a financial deregulation.

Another factor, one that may be crucial for the likelihood of a large-scale financial deregulation, is of course the previous state of the financial sector. If the financial sector is heavily regulated, or works poorly, politicians may very well want to improve it drastically, "give it a big bang". It has unfortunately proven hard to get a good measurement on the performance of financial markets, especially for the U.K. The Financial Development and Structure Dataset by Beck, Demirgüç-Kunt and Levine (2010) does not include any data on the size or efficiency of the British financial sector until after 1989, and the internal data from the London Stock exchange is not available before 1997, which makes it hard to control for the de facto status of the British financial sector. There is, however, data for Japan in terms of the stock market capitalization (Beck et al. 2010a), which will be included as a control variable for Japan.

Hence, to capture this effect for the U.K., some kind of de jure index of financial market liberalization could be used to ensure the preconditions are the same. Studies concerned with the international openness of the financial systems have previously used IMF data on the presence of financial regulations, which is a quite crude measurement on the level of liberalization. This data has been used to construct more detailed indexes, trying to capture the quality of the regulation. The most comprehensive seems to be the Quinn (1997) index, which takes the qualitative aspects of specific regulations into account (Vlachos and Waldenström, 2005). This index will be used in the baseline specification for the test of both the U.K. and the Japanese big bang.

Other datasets have also been considered as a measure of financial deregulation. First, the research into equity market liberalization by Bekaert, Harvey and Lundblad (2006) presents both de jure and de facto measures of important financial deregulations concerning the equity market. Unfortunately, their research focus entirely on developing countries, why data for OECD countries have not been collected. Another index based on the IMF data but with a more qualitative approach is the KAOPEN index developed by Chinn and Ito (2008). This index also measures the judicial financial 
Table A2: Description of control variables

\begin{tabular}{|c|c|c|}
\hline Controls used & Description of variable & Source \\
\hline TaxIndICP & $\begin{array}{l}\text { Tax revenue from individuals on } \\
\text { income, profits and capital gains } \\
(\% \text { of GDP) }\end{array}$ & OECD iLibrary (2015-02-25) \\
\hline TopTaxRate & The highest marginal inocme tax rate & Piketty et al., 2014 \\
\hline growth & Annual GDP growth $(\%)$ & World Development Indicator** \\
\hline GDPPCcur & GDP per capita, current prices & World Development Indicator** \\
\hline exports & $\begin{array}{l}\text { Exports of goods and services } \\
(\% \text { of GDP) }\end{array}$ & World Development Indicator** \\
\hline imports & $\begin{array}{l}\text { Imports of goods and services } \\
(\% \text { of GDP) }\end{array}$ & World Development Indicator** \\
\hline GDPPCcons & GDP per capita, constant 2005 USD & World Development Indicator** \\
\hline ka_open & $\begin{array}{l}\text { Index of financial openness in capital } \\
\text { account transactions, normalized }\end{array}$ & Chinn and Ito, 2012 \\
\hline rightwing & Right-wing executive & DPI, World Bank. Keefer, 2012 \\
\hline pr & Proportional voting system & DPI, World Bank. Keefer, 2012 \\
\hline SM & $\begin{array}{l}\text { Stock Market, } \\
\text { financial liberalization index }\end{array}$ & Kaminsky and Schmukler, 2008 \\
\hline DFS & $\begin{array}{l}\text { Domestic Financial Sector, } \\
\text { financial liberalization index }\end{array}$ & Kaminsky and Schmukler, 2008 \\
\hline Unemp & Unemployment rate & OECD iLibrary (2015-02-25)* \\
\hline current_quinn & $\begin{array}{l}\text { Quinn index, } \\
\text { restrictions to the current account }\end{array}$ & Quinn, 1997 \\
\hline capital_quinn & $\begin{array}{l}\text { Quinn index, } \\
\text { restrictions to the capital account }\end{array}$ & Quinn, 1997 \\
\hline epl & $\begin{array}{l}\text { Employment protection legislation } \\
\text { (OECD data) }\end{array}$ & Nickell, 2006 \\
\hline $\mathrm{uc}$ & Union coverage (combinaton of data) & Nickell, 2006 \\
\hline cellphone & Number of cell phones per capita & CHAT, Comin and Hobijin, 2009 \\
\hline SMC_GDP & $\begin{array}{l}\text { Stock market capitalization } \\
(\% \text { of GDP })\end{array}$ & Beck et al., 2010a \\
\hline ger_mom & Legal origin: Germany (Japan) & La Porta et al., 1997 \\
\hline uk_mom & Legal origin: United Kingdom & La Porta et al., 1997 \\
\hline rule_law & Rule of law & La Porta et al., 1997 \\
\hline
\end{tabular}

* Unemployment rate for France and U.K. complemented with national statistics data from INSEE and ONS.

** The World Bank (Updated: 2015-01-30) 
Table A3: Control variables in the selection of the Synthetic Control Group

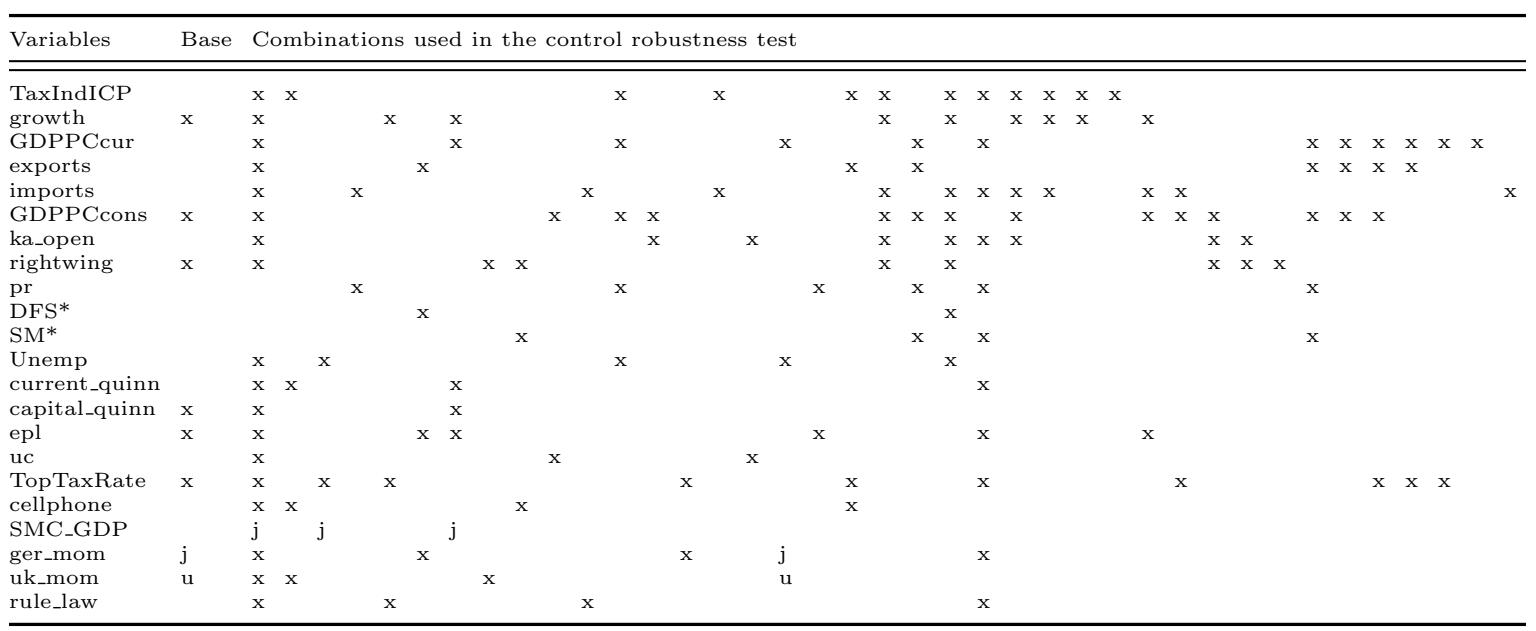

Table A4: Years in Synthetic control group choise function

\begin{tabular}{rrr|rrr}
\hline \multicolumn{3}{c}{ United Kingdom } & \multicolumn{3}{c}{ Japan } \\
\hline \hline Baseline & Version 2 & Version 3 & Baseline & Version 2 & Version 3 \\
1971 & 1971 & 1979 & 1981 & 1981 & 1991 \\
1976 & 1973 & 1982 & 1985 & 1983 & 1994 \\
1979 & 1975 & 1984 & 1990 & 1985 & 1996 \\
1982 & 1977 & 1986 & 1993 & 1987 & \\
1985 & 1979 & & 1997 & 1989 & \\
& 1981 & & & 1991 & \\
& 1983 & & & 1993 & \\
& 1985 & & & 1995 & \\
& & & & & \\
\end{tabular}

openness, but it also takes the interaction effect of different regulations into account, and it correlates well with more advanced indices.

Since the deregulations of interests in this study concern stock markets and internal financial markets, rather than international openness, neither the Quinn index nor the Chinn-Ito index may capture the relevant effect. Instead, specific indexes for the regulatory environment in these areas, developed by Kaminsky and Schmukler (2003), could be used. These indexes rate the financial environment from one to three, one being the least liberalized (Kaminsky and Schmukler, 2003). The Kaminsky and Schmukler indices will be used for the domestic financial sector and for the stock market, but only in alternative control specifications, since data is unavailable for several countries in the donor pool. Both the Kaminsky-Schmukler and Chinn-Ito indexes will be used in alternative specifications of the control variable, as a robustness test.

Also Abiad et al. (2008) have separate indices for different dimensions of deregulation. A few of these are included as a reference in appendix A3. This appendix is a very detailed description of the general level of deregulation in all countries at the time. 
The index value for all of the indices presented above for all countries are presented in figure A2.

For both the U.K. and Japan, most regulations regarding foreign ownership was abolished earlier than the big bangs, why both markets are considered fully liberalized at the time of the big bangs by most indices and sources, see tables A5 and A6.

As noted in the main text, the big bangs were not introducing basic freedoms of transaction, which were already in place. They instead meant additional lowering of entry barriers and firm size regulations, which gave an extra boost to the country in terms of financial market international competitiveness. The other OECD countries are experiencing deregulations during the time period, which means the counterfactual will not consist of countries with a static financial sector, but rather the "Big Bang" will be compared to a "normal" financial market evolution during the time period.

Figure A1: Robustness of the synthetic control with respect to financial development indices
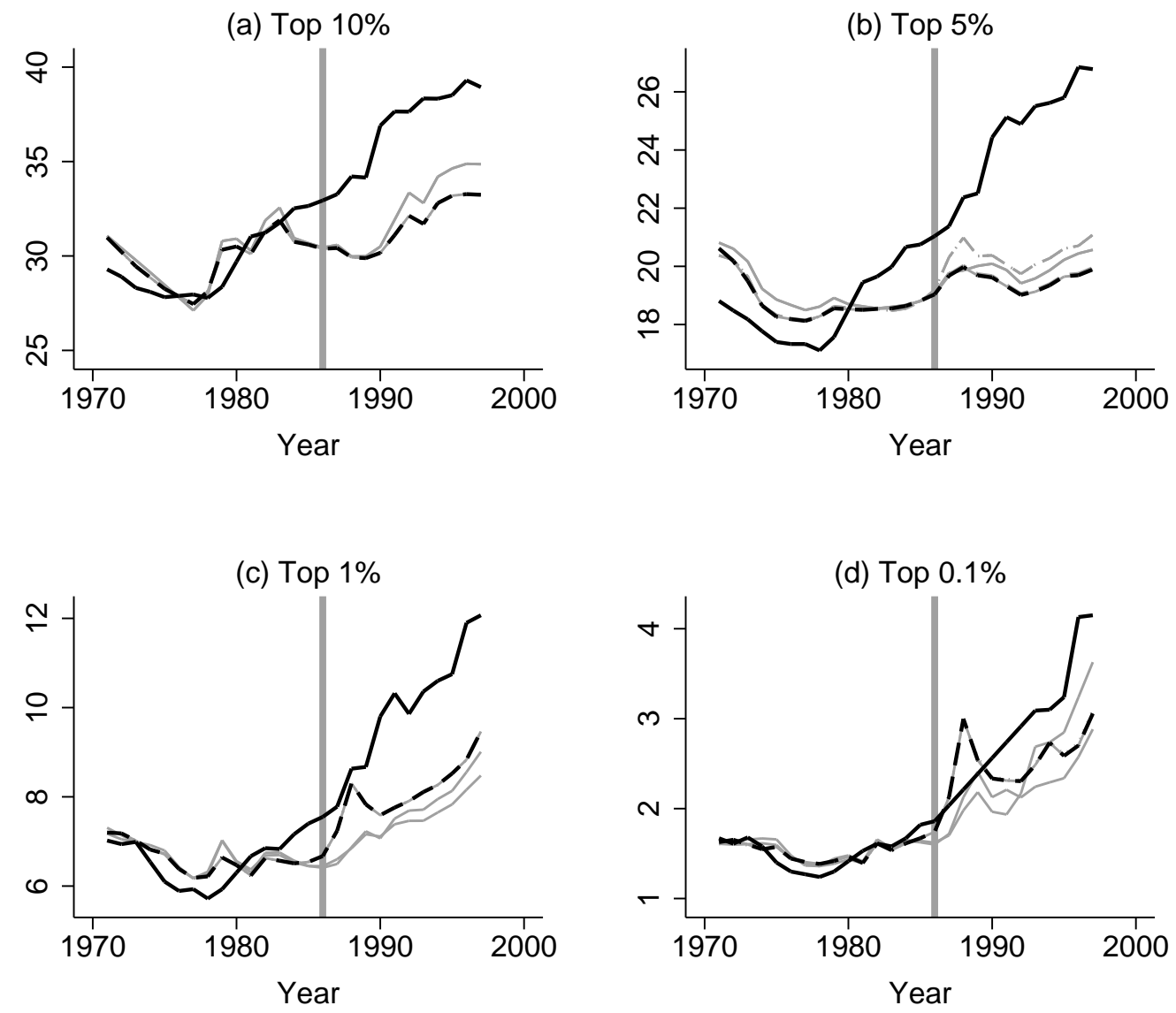

Unless data on the real size or efficiency of the financial market or stock market exchange is available, it will be hard to fully prove that one deregulation was more effective than another. Rating the relevance of new policies is always a matter of judgement, and the discrepancy between these different indices is natural, though 
problematic. Based on previous research (Roine et al., 2009) and the level of detail, we have chosen to use the Quinn index on capital accounts in the baseline specification of the results. The reader is advised to consult appendix A.3 as well as the sources to judge the relative importance of the big bang deregulations.

A test of the relevance of the capital Quinn index relative to other indices of financial development was made in order to find the best pre-treatment fit of the synthetic control group for the UK. The result of this test for all top income shares is shown in figure A1. The black line represents the synthetic control when the Quinn index is used, and the grey lines represent the current Quinn index, the KAOPEN index, "Domestic Financial Sector" and "Stock market liberalization" from Kaminsky and Schmukler (2008), and the variables Entry barriers, Banking supervision, Security markets and Financial Reform from Abiad et al. (2008). All of these measures are discussed in the following section.

None of the alternative indices are providing a better pretreatment trend than the Quinn index. In fact, the Root Mean Squared Prediction Error for the Quinn index is smaller than or equal to the RMSPE for all other indices tested, though the differences are very small.

\section{A.4 Financial Deregulations in other Countries}

The Big Bangs studied in this paper are large-scale deregulations, aimed to improve the stock market trade and increase the international competitiveness of London's (Bellringer and Michie, 2014) and Tokyo's (Toya and Amyx, 2006, p.192) stock exchanges respectively. Other liberalizations of the financial markets were common in all OECD countries during this period, for example a majority of OECD governments ceased to regulate interests (Girouard and Blöndal, 2001). Since we aim to study the effect of the Big Bangs relative to a more standard process of deregulations, the fact that other liberalizations occurred in the countries included in the synthetic control groups during his time period is not necessarily a problem, but it is important to note the effect it may have on the synthetic control groups.

In this section, deregulations in other industries are described, using two different text sources and several indexes of financial liberalization. Summaries of the major deregulations according to OECD (Girouard and Blöndal, 2001) and Williamson and Mahar (1998) are summarized in table A5 and A6. The index values for each country are shown in figure A2.

The Current and Capital Quinn indexes are from the dataset by Quinn (1997), the Chinn-Ito, or Kaopen index is from Chinn and Ito (2008), the specific indexes for reforms in entry barriers, banking supervision and security markets are collected by Abiad et al. (2008) and the domestic financial sector and stock market indexes are taken from Kaminsky and Schmukler (2003).

The different indices identify different years as important reform years, and this discrepancy is only partially because of a focus in different areas. Figure A2 show a general trend of less regulations in the financial sector, and the level of liberalization in both the U.K. and Japan prior to their respective big bang seem similar to other 
countries in the donor pool.

During the period of the Japanese Big Bang, there were a few minor deregulations in Spain, Switzerland and the U.S. (registered by the Capital Quinn index for Spain, Improved banking regulation for Switzerland and Decreased entry barriers in the U.S., all in 1999). This is considered a normal pace of deregulations, and having a major effect on the financial industries in these countries.

One cause of concern, however, is the Canadian data where a major financial liberalization in banking supervision occurred in 1986. This could bias the results, since Canada is a part of the synthetic control groups for the U.K. top 1 and 0.1 percent income groups. Similarly, there is an increase in the domestic financial sector for Ireland 1986-1987 (Kaminsky and Schmukler's index), which may be directly related to the deregulations in the neighboring country. If these changes had an impact on financial services in the same way as the British Big Bang, it may cause an underestimation of the impact of the Big Bang on top income shares.

Table A5: Important financial deregulations 1

\begin{tabular}{|c|c|c|c|}
\hline & \multicolumn{3}{|c|}{$\begin{array}{l}\text { Girouard and Blöndal (2001) } \\
\text { Deregulations affecting the housing markets Table } 3\end{array}$} \\
\hline & Beginning & Main deregulation & Description \\
\hline Australia & 1980 & 1985 IR & $\begin{array}{l}\text { Bank specialisation requirements eliminated } \\
\text { for large domestic banks in } 1980 \text {. } \\
\text { Quantitative bank lending guidance eliminated in } 1982\end{array}$ \\
\hline Canada & 1967 IR & $1980,1987 \mathrm{~S}$ & Banks allowed to have mortgage loan subsidiaries in 1980 \\
\hline Denmark & $1982 \mathrm{IR}$ & $1989,1991 \mathrm{EEC}$ & Elimination of restrictions on mortgage bond issuance \\
\hline $\begin{array}{l}\text { Finland } \\
\text { France }\end{array}$ & 1986 IR & $1987,1989 \mathrm{~S}$ & Government withdrew guidelines on mortgage lending in 1987 \\
\hline $\begin{array}{l}\text { Germany } \\
\text { Ireland }\end{array}$ & 1967 IR & $1992 \mathrm{EEC}$ & \\
\hline Italy & 1983 IR & $1993 \mathrm{EEC}$ & $\begin{array}{l}\text { Credit ceilings eliminated in } 1983 \text { and temporarily } \\
\text { re-imposed in 1986-87. Separation of long-term and } \\
\text { short-term credit institutions abolished in } 1994\end{array}$ \\
\hline Japan & 1993-1994 IR & & \\
\hline Netherlands & $1980 \mathrm{IR}$ & $1992 \mathrm{EEC}$ & \\
\hline New Zealand & 1984 IR & & \\
\hline $\begin{array}{l}\text { Norway } \\
\text { Portugal } \\
\text { Spain }\end{array}$ & 1984 & 1985 IR & Lending controls abolished in 1984 \\
\hline $\begin{array}{l}\text { Sweden } \\
\text { Switzerland }\end{array}$ & 1985 IR & & Lending ceilings for banks abolished in 1985 \\
\hline United Kingdom & 1980 "the Corset" & $\begin{array}{l}1986 \\
1987 \mathrm{~S}, 1993 \mathrm{EEC}\end{array}$ & $\begin{array}{l}\text { Bank of Englands minimum lending rate abolished in } 1981 \\
\text { Banks allowed to compete with building societies for } \\
\text { housing finance after } 1981 \text {. Building societies allowed to } \\
\text { expand their lending business after } 1986 \text {. Government } \\
\text { withdrew guidelines on mortgage lending in } 1986 \text {. }\end{array}$ \\
\hline United States & $1971 \mathrm{~S}$ & 1980 IR & $\begin{array}{l}\text { Interest rate deregulation, phasing out over four years }(1980-84) \\
\text { Elimination of portfolio restrictions for thrifts in } 1980 \text {. }\end{array}$ \\
\hline
\end{tabular}

Note: IR - deregulation of interest rates. Prior to the deregulations, caps on interest rates charged by retail banks were possible.

EEC - Implementation of the European Union's Second Banking Directive (89/646/EEC) .

$\mathrm{S}$ - Securitization allowed (The possibility to combine several assets into one instrument, and selling shares of this instrument as a security in order to decrease risks.)

\section{A.5 Outcomes of the control group countries}

To better understand what drives the synthetic control trends, we have looked at the evolution of control variables and top income shares for the countries in the synthetic control groups. First, figures A3 and A4 show the unweighted trends in top incomes for the most important countries in the SCG for each income group.

A potential cause for concern regarding synthetic control trends would be that the trend it projects is largely different from the trends in any real country. For example, 
Figure A2: Indexes of financial liberalization and deregulation
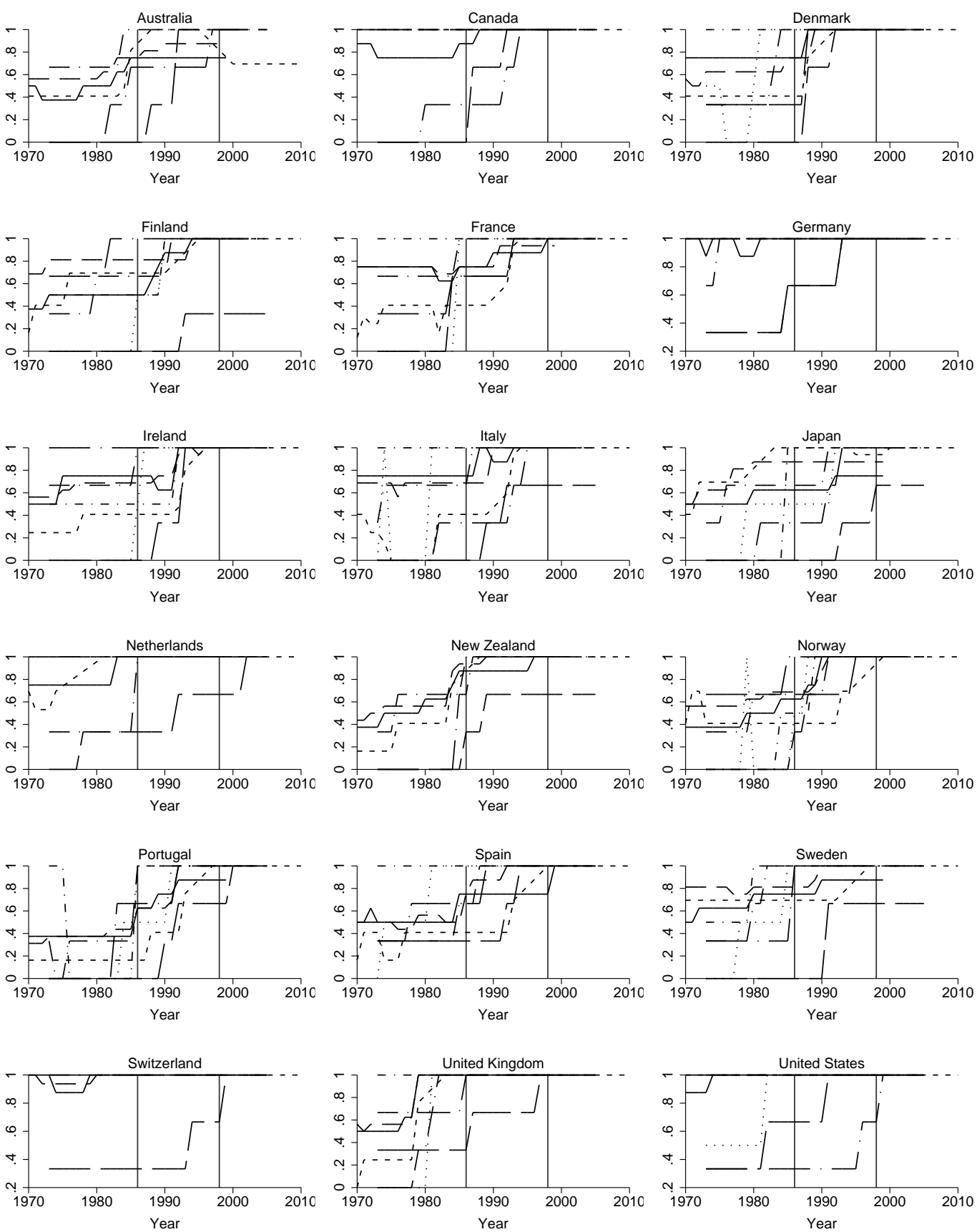

\begin{tabular}{lll} 
Capital Quinn index & - - Current Quinn index & $\cdots$ Chinn-Ito index \\
Entry barriers & - Banking supervision & - Scurity markets \\
… Domestic Financial Sector & - - Stock market liberalization index & \\
\hline
\end{tabular}


Table A6: Important financial deregulations 2

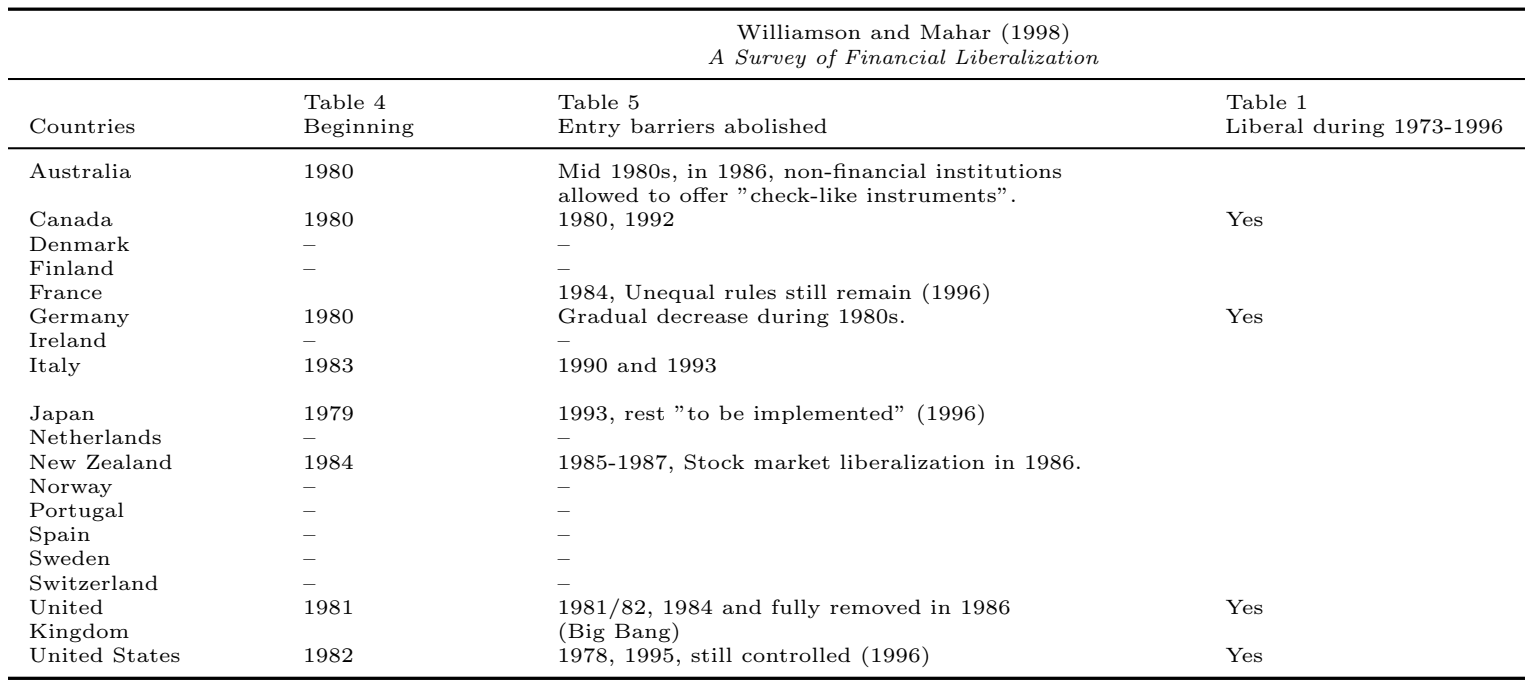

a constant synthetic trend could in fact be created by combining one increasing and one decreasing trend. The assumption that the counterfactual would be a stable path seems less likely in that case. Such false trends do not seem likely in this case however. For the U.K., Figure A3 show increasing trends for all countries except the Netherlands, though all trends seem to increase less steeply than the British top income shares. The spike in the Australian data in 1987 is also clearly visible in panels A3.c and A3.d. The synthetic controls for Japan are to some extent "lifted" by the high top income figures for the U.S., but except for this ant the Spanish top 0.1 percent, all control countries seem to share a stable or mildly increasing trend. 
Figure A3: Countries in synthetic control, United Kingdom
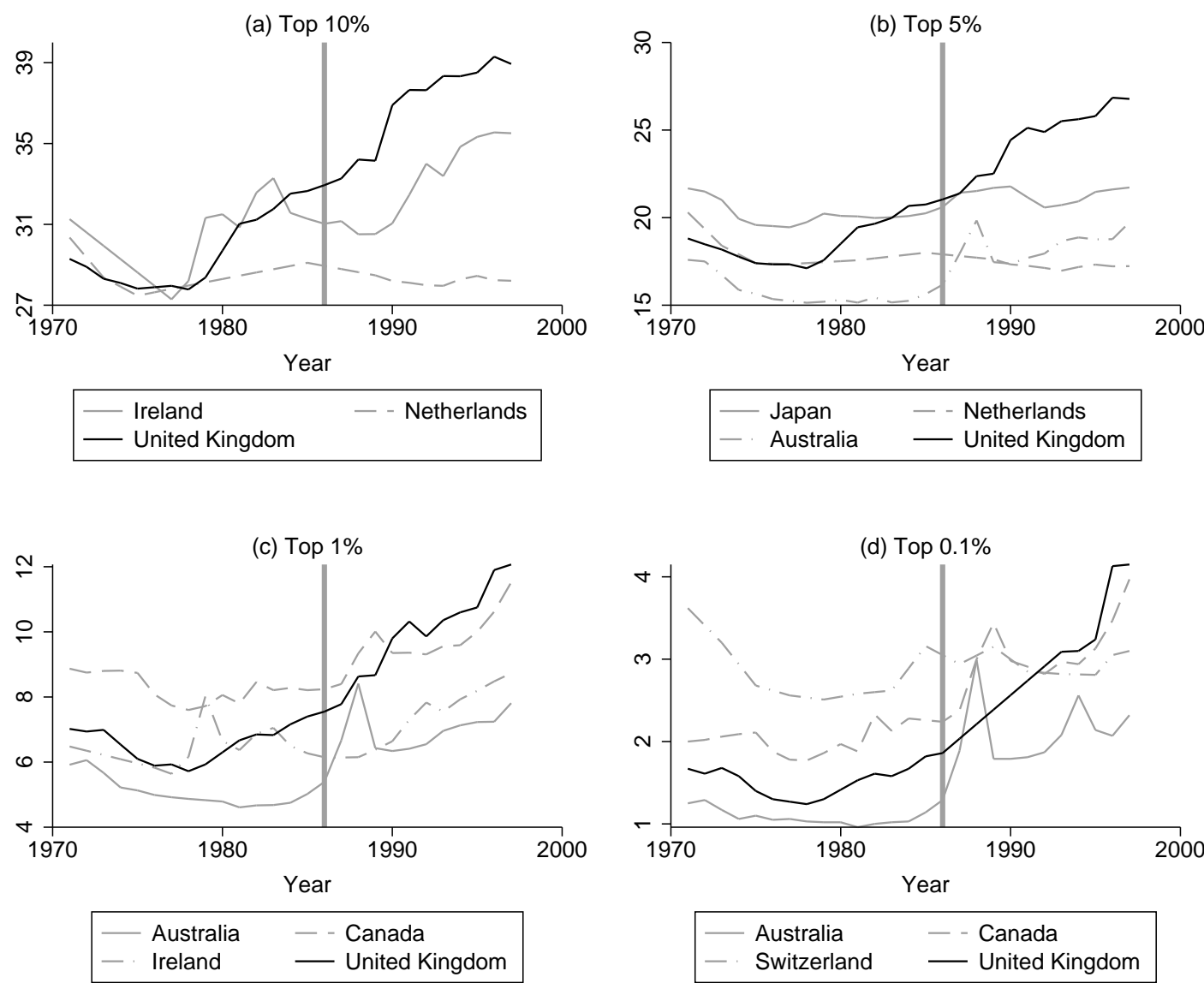
Figure A4: Countries in synthetic control, Japan

(a) Top 10\%

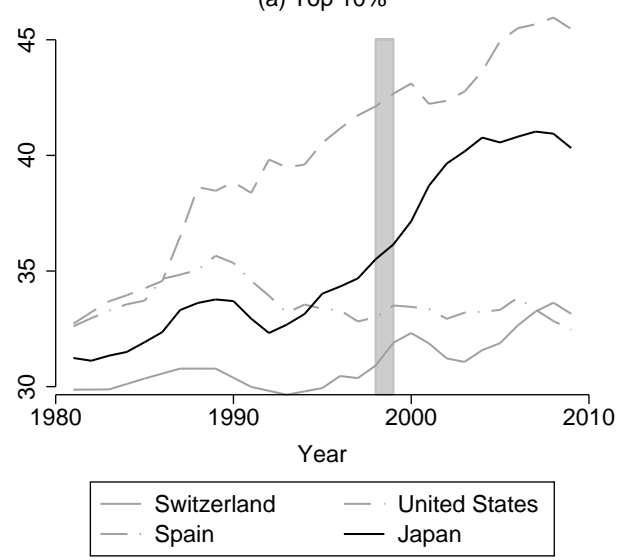

(c) Top 1\%

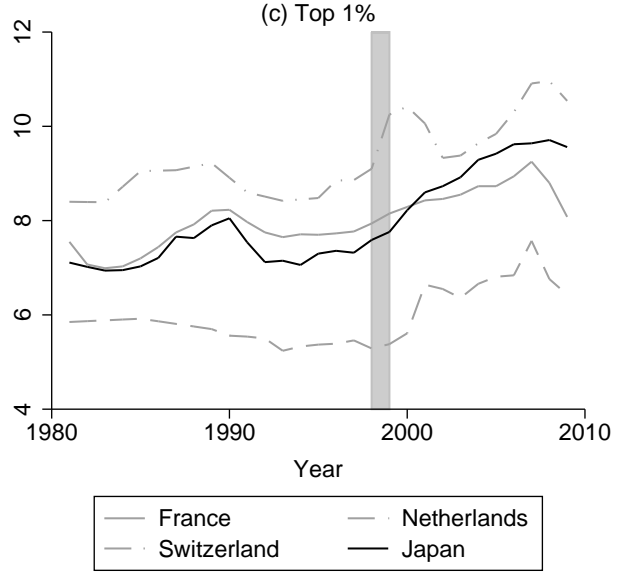

(b) Top 5\%

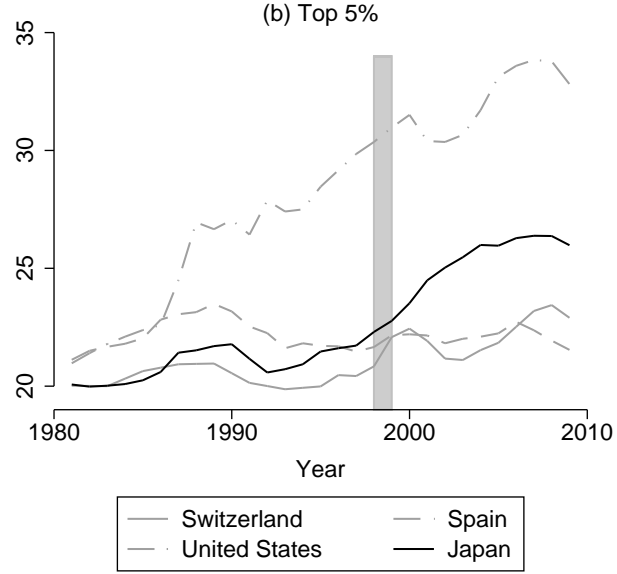

(d) Top $0.1 \%$

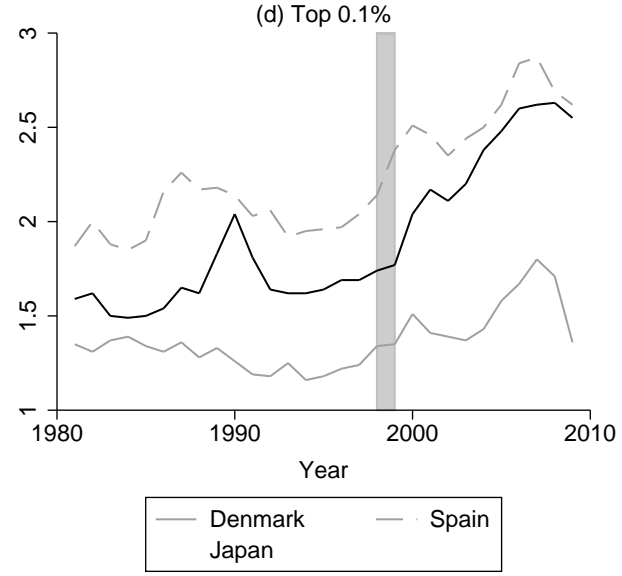




\section{B Results Appendix}

\section{B.1 Shorter control period for the U.K.}

The synthetic control groups for the top 10 and top 5 percent income shares in the U.K. fail to capture the pre-treatment trend in top incomes. To test if this is due to a too long pre-treatment period, the results for the top income shares are reproduced using only the period 1979-1986 as the pre-treatment period. The characteristics of the new synthetic control groups are described in table A7 and A8, and the results are shown in figure A5.

The top 1 and 0.1 percentile results are also shown, for completeness. The control years used in the optimization function are presented in column 2 of table A4. In the standard setting both the time period over which the control variables are averaged and the period over which the mean squared prediction error is minimized and set to 1971-1986. In this alternative specification, both of these periods are shortened.

Canada seems to be a better match for this new, shorter specification, and also Japan and the Netherlands are important composition. Ireland is no longer a relevant control country. For the top 5 and 10 income groups, the political control variables of rightwing executive and top income tax rate fit very well in both the baseline specification in table A7 and in the new specification, table A8. The fit for employment protection and British origin have worsened compared to the baseline model, and so has the fit for the Quinn index, but this is only because of a large change in the U.K. average (the Quinn index defines U.K. as fully liberalized after 1979). The economic indicators of growth and GDP per capita are only slightly improved.

The shorter specification is not unambiguously improving the match in terms of control variables, neither does it succeed to satisfyingly capture the true U.K. trend. As Figure A5 shows, the level of the top income in the synthetic control group has increased, but the trend is constant and still fail to match the increase during the 1980s. On the contrary, for the top 10 percent group, the new synthetic control actually has a worse fit, since the baseline synthetic control at least capture the increase in trend from 1979 to 1983 .

The conclusion from this additional test is that shortening the pre-treatment time does not improve the synthetic control group match in terms of following the increase in trend for the U.K. It therefore seems like the donor pool cannot provide a good estimation for this trend (at least not without extrapolation). This indicates that the evolution in the U.K. before the Big Bang was exceptional, and hence it is hard to find a good comparison. 
Table A7: Countries in synthetic control group, United Kingdom

\begin{tabular}{lrrrr}
\hline & Top $10 \%$ & Top $5 \%$ & Top $1 \%$ & Top 0.1 \% \\
\hline \hline Australia & 0 & 0 & 0.438 & 0.56 \\
Canada & 0.216 & 0 & 0.222 & 0.255 \\
Denmark & 0 & 0 & 0 & 0 \\
Finland &. & 0 & 0 &. \\
France & 0 & 0 & 0 & 0 \\
Germany & 0 & 0 & 0 & 0 \\
Ireland & 0 & 0 & 0 &. \\
Italy & 0 & 0 & 0 & 0 \\
Japan & 0.355 & 0 & 0 & 0 \\
Netherlands & 0.434 & 0.212 & 0 & 0 \\
NewZealand & 0 & 0 & 0 & 0 \\
Norway & 0 & 0 & 0 & 0.019 \\
Sweden & 0 & 0 & 0.339 & 0.165 \\
Switzerland & 0 & 0.788 & & 0 \\
\hline
\end{tabular}

Table A8: Comparison of control variables, United Kingdom

\begin{tabular}{lrrrrrr}
\hline Control variables & U.K. & \multicolumn{3}{c}{ Synthetic control groups } & Mean* \\
& & Top 10 \% & Top 5 \% & Top 1 \% & Top 0.1 \% & \\
\hline \hline GDP growth & 1.99 & 2.65 & 1.56 & 2.53 & 2.77 & 2.58 \\
GDP per capita & 23179 & 24797 & 39851 & 29638 & 26037 & 24805 \\
Right-wing Executive & 0.88 & 0.86 & 0.21 & 0.36 & 0.45 & 0.4 \\
British origin & 1 & 0.21 & 0 & 0.66 & 0.81 & 0.28 \\
Employment protection & 0.20 & 0.70 & 0.45 & 0.30 & 0.31 & 0.72 \\
Quinn Index & 100 & 76.2 & 97.4 & 77.3 & 71.1 & 70.3 \\
Top Income Tax Rate & 0.60 & 0.65 & 0.50 & 0.49 & 0.52 & 0.64 \\
\hline
\end{tabular}


Figure A5: The British "Big Bang" in 1986
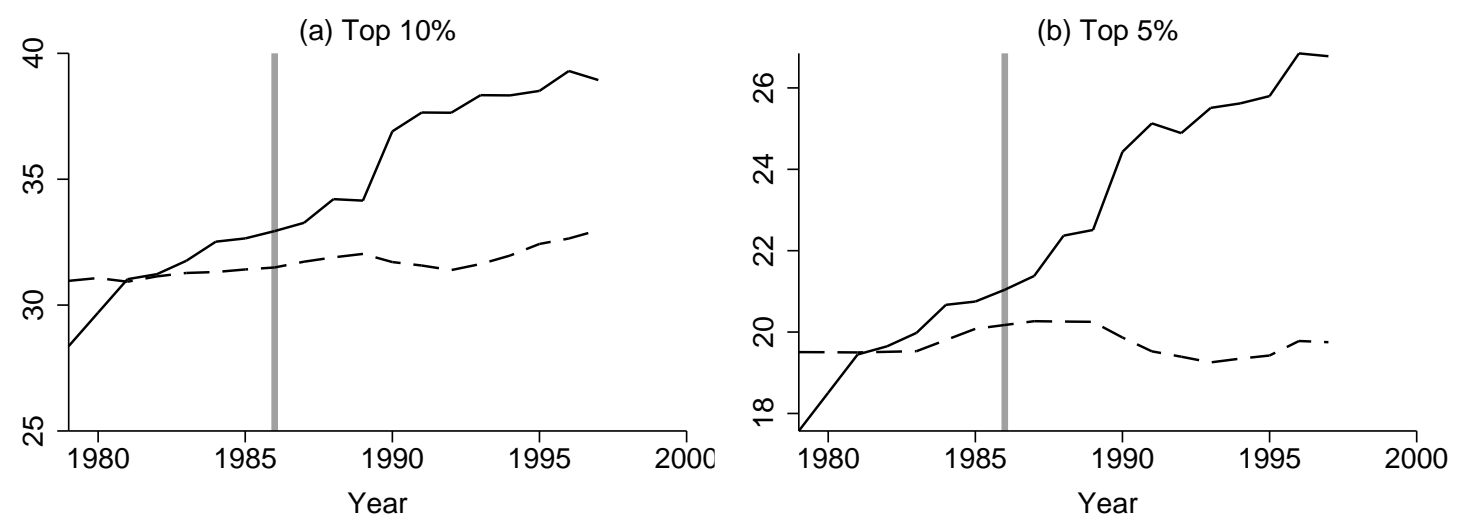

(c) Top 1\%

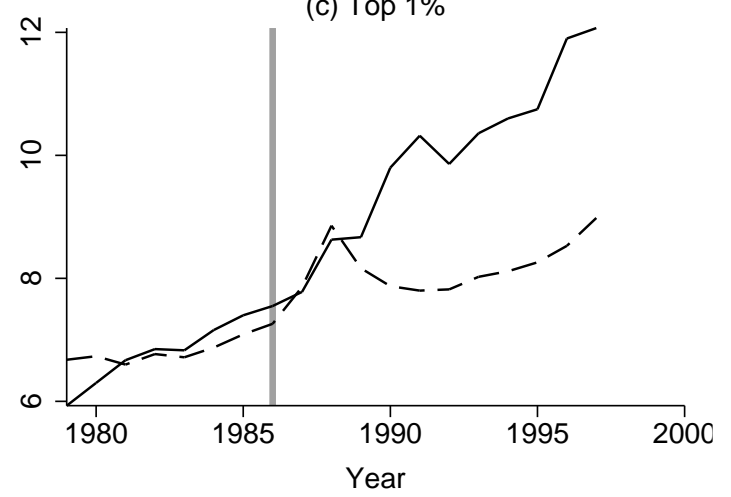

(d) Top $0.1 \%$

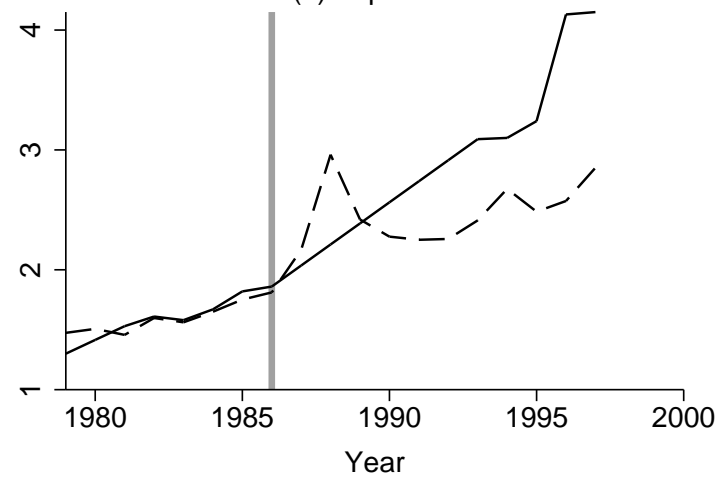

\section{United Kingdom $\quad----$ Synthetic United Kingdom}

Note: Control groups optimized over the time period 1979-1985 


\section{B.2 Synthetic control composition for intermediate shares}

In tables A9 and A10 the countries that constitute the synthetic control groups for the intermediate shares. Rather than calculating differences between the original control groups, the effect on the intermediate groups have been estimated by new SCGs representing the 90th to 95th percentile, the 95th to 99th percentile and the bottom nine thousandth respectively. Even though the same control variables are used, different trends for the intermediate shares among countries may affect the composition of the SCG, and hence also the point estimates of the treatment effects (therefore, adding up the intermediate shares will not necessarily give the same graph as the baseline, top $10 \%$ graph.)

The fit with regards to the control variables are presented in A11. The problems with matching on the control variables seem to be of the same magnitudes as for the baseline estimation. See section 5.3 for a discussion of this.

Table A9: Countries in synthetic control group, United Kingdom

\begin{tabular}{lrrr}
\hline Percentile Groups & 90th to 95th & 95th to 99th & 99th to 99.9th \\
\hline Australia & 0 & 0 & 0.152 \\
Canada & 0.138 & 0 & 0 \\
Denmark & 0 & 0 & 0 \\
Finland & $\cdot$ & 0 & 0 \\
France & 0 & 0 & 0 \\
Germany & 0 & 0 & 0.611 \\
Ireland & - &. & 0 \\
Italy & 0 & 0 & 0 \\
Japan & 0 & 0.3 & 0 \\
Netherlands & 0.862 & 0 & 0 \\
NewZealand & 0 & 0 & 0 \\
Norway & 0 & 0 & 0 \\
Sweden & 0 & 0 & 0.237 \\
Switzeerland & 0 & & 0 \\
\hline
\end{tabular}

\section{B.3 A Unified synthetic control country for all top income shares}

An alternative approach to creating synthetic control groups would be to construct a single synthetic country to plot the counterfactual trend for all top income shares. Rather than having four different combinations of countries to represent the U.K (Japan), here we present a single synthetic country, which was optimized on the trends of the top 10, top 5, top 1 and top 0.1 percent simultaneously. ${ }^{26}$

The resulting synthetic countries are a combination of the Netherlands, Canada, Japan and Switzerland for the U.K. and France, Spain and Australia for Japan, see table A12. All of these countries are represented in the income group-specific SCG's as well, but some countries fall out in the unified group.

\footnotetext{
${ }^{26}$ Note that this estimation was done with a different program than the synthetic control groups in the paper, the originals using Stata and this optimization using Matlab. Both programs are available at http://web.stanford.edu/ jhain/synthpage.html
} 
Table A10: Countries in synthetic control group, Japan

\begin{tabular}{lrrr}
\hline Percentile Groups & 90th to 95th & 95th to 99th & 99th to 99.9th \\
\hline Australia & 0 & 0 & 0.13 \\
Canada & 0.542 & 0 & 0 \\
Denmark & 0 & 0 & 0.016 \\
Finland &. & 0.011 &. \\
France & 0.395 & 0 & 0 \\
Italy & 0.063 & 0 & 0 \\
Netherlands & 0 & 0 &. \\
New Zealand & 0 & 0 &. \\
Norway & 0 & 0.105 & 0 \\
Spain & 0 & 0.328 & 0.264 \\
Sweden & 0 & 0 & 0 \\
Switzerland & 0 & 0 & 0.591 \\
United States & 0 & 0.557 & 0 \\
\hline Not Thy
\end{tabular}

Note: The synthetic control groups are composed of the weighted average of countries presented in the table. The weights are chosen as they represent best fit to each different top income trend and control variables prior to the treatment.

A unified synthetic country is theoretically more justifiable as the best counterfactual as long as the same unobservables are expected to affect the different shares of top income earners similarly. But unfortunately, the fit of the pre-treatment trend in the unified case are considerably worse than the fit for share-specific SCG's. This is clearly seen by comparing the Black dashed lines in figures A6 and A7 to the originalgray-lined SCGs. Though the unsatisfactory pre-treatment fit makes these results less reliable, they indicate that the effect of the Big Bangs are still notable, and larger for all estimates except for the very top of Japanese income shares.

\section{B.4 Effect of including capital gains in top incomes}

Higher wealth returns as an explanation to a positive deregulation effect on top incomes was discussed above. While we are lacking the data necessary to construct synthetic control groups for different sources of income in the top groups, some countries report top shares for incomes either excluding realized capital gains (these are used in our main analysis) and including realized capital gains. The realized capital gains observed in the tax statistics are problematic for many reasons, but still interesting to consider if possible. They do not cover all capital gains but only those that are visible upon realization, and this also means that their timing may be wrong since when they are realized is not necessarily the same time as they occurred. ${ }^{27}$ That said, capital gains, appropriately measured, are part of the classical Haig-Simons definition of income and studies have shown that observed realized capital gains are indeed correlated with other incomes in the top of the income distribution (Roine and Waldenström, 2012).

${ }^{27}$ An additional problem is that the tax rules differ across countries regarding capital gains, which means that the amounts reported on tax returns may reflect different shares of the total amount of realized capital gains. We discuss these problems at length in the appendix. 
Figure A6: Unified Synthetic Control Group Trend, United Kingdom

(a) Top 10\%

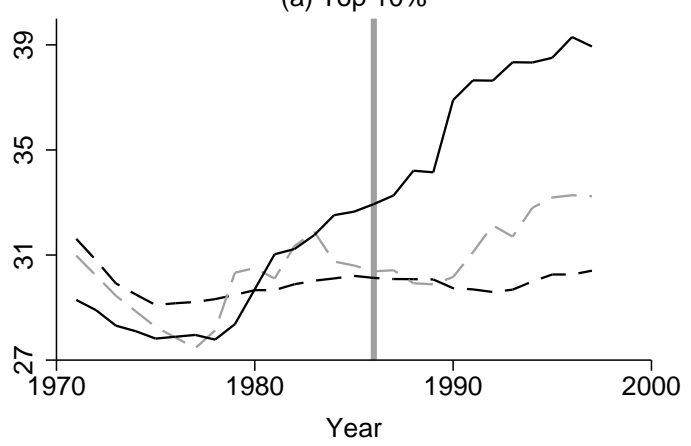

(c) Top $1 \%$

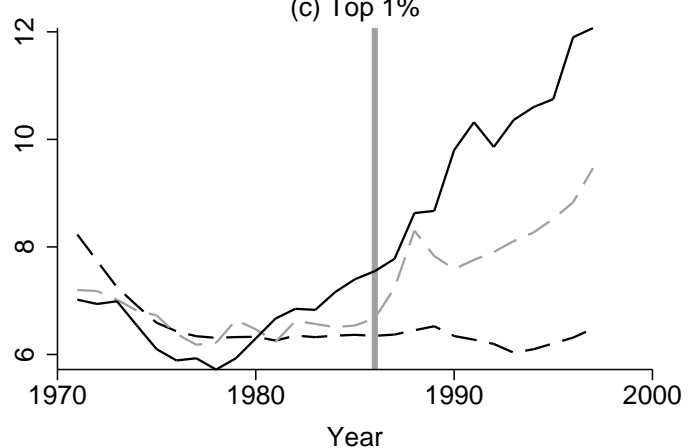

(b) Top 5\%

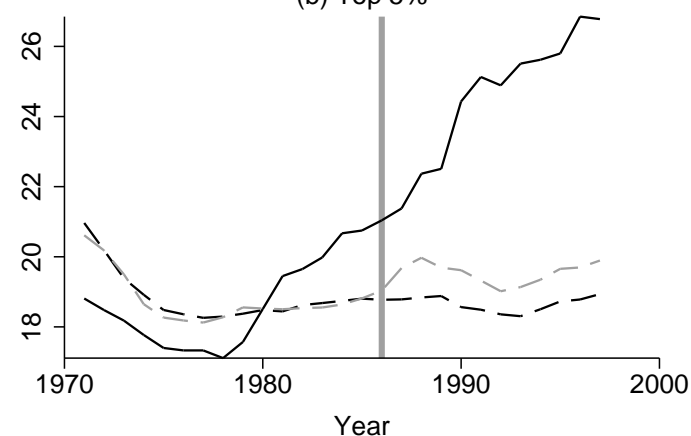

(d) Top $0.1 \%$

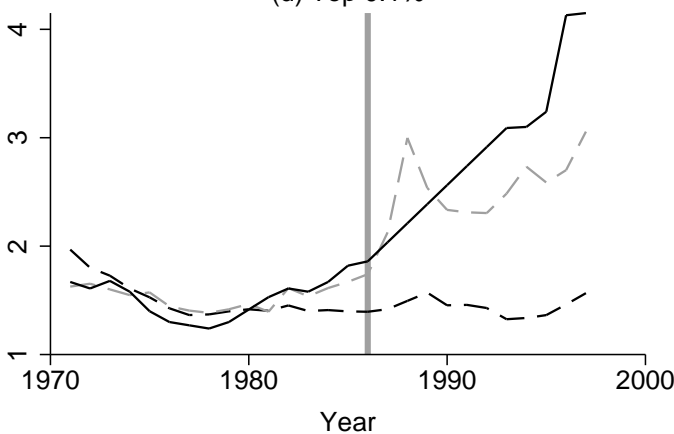

- - Synthetic control Country (same for all top incomes) $\quad-$ - Baseline SCG United Kingdom 
Figure A7: Unified Synthetic Control Group Trend, Japan
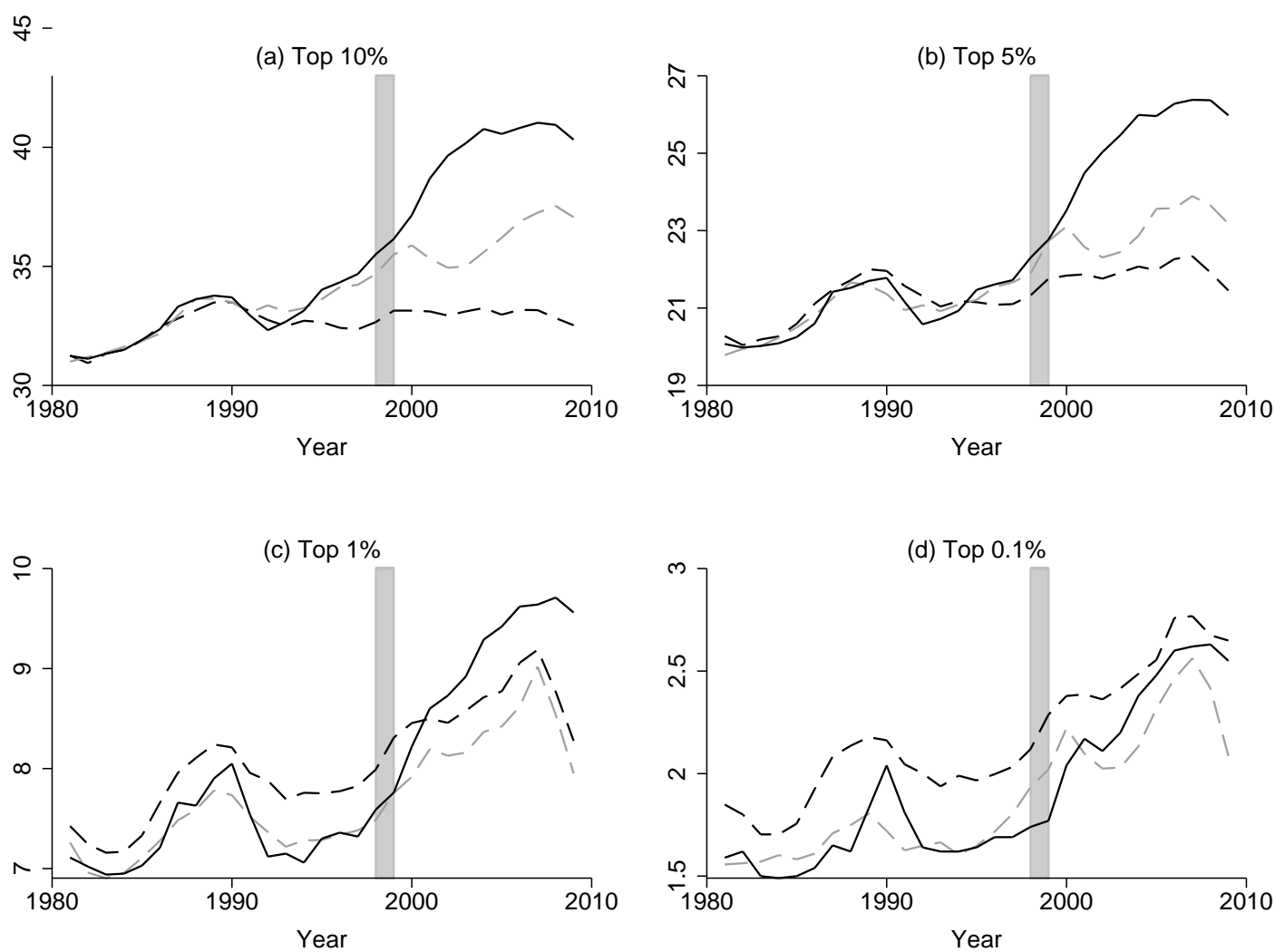

- - Synthetic control Country (same for all top incomes) $\quad-$ - Baseline SCG
- Japan 
Table A11: Comparison of control variables, United Kingdom

\begin{tabular}{|c|c|c|c|c|c|}
\hline & U.K. & \multicolumn{2}{|c|}{ Synthetic control groups } & & Mean* \\
\hline & \multicolumn{5}{|c|}{ 90th to 95 th 95 th to 99 th 99 th to 99.9 th } \\
\hline GDP growth & 2.24 & 2.54 & 2.97 & 3.12 & 2.58 \\
\hline GDP per capita & 21688 & 24901 & 23712 & 23246 & 24805 \\
\hline Rightwing executive & 0.63 & 0.62 & 0.78 & 0.52 & 0.4 \\
\hline U.K. legal origin & 1 & 0.14 & 0 & 0.76 & 0.28 \\
\hline Employment protection & 0.19 & 0.81 & 0.84 & 0.29 & 0.72 \\
\hline Capital Quinn Index & 76.6 & 80.8 & 73.5 & 72.4 & 70.3 \\
\hline \multirow[t]{3}{*}{ Top Income Tax Rate } & 0.68 & 0.68 & 0.72 & 0.59 & 0.64 \\
\hline & Japan & Syntl & control groups & & Mean* \\
\hline & \multicolumn{5}{|c|}{ 90th to 95 th 95 th to 99 th 99 th to 99.9 th } \\
\hline GDP growth & 3.40 & 2.26 & 3.0 & 2.03 & 2.05 \\
\hline GDP per capita & 28608 & 26843 & 28522 & 35974 & 32510 \\
\hline Rightwing executive & 0.88 & 0.36 & 0.46 & 0.06 & 0.38 \\
\hline German legal origin & 1 & 0 & 0 & 0.59 & 0.22 \\
\hline Employment protection & 0.70 & 0.60 & 0.54 & 0.57 & 0.78 \\
\hline Capital Quinn Index & 66.9 & 86.4 & 87.5 & 88 & 90.3 \\
\hline Top Income Tax Rate & 0.60 & 0.45 & 0.46 & 0.47 & 0.53 \\
\hline Stock Market Capitalizaton & 82.9 & 43.4 & 55.8 & 74.6 & 51.3 \\
\hline
\end{tabular}

Note: Means of the control variables used to find the optimal synthetic control group in the pretreatment time period. For a good counterfactual, each synthetic control group should have control variable means that are close to the mean of the control variables for the treated country. The control variables are described in table 1.

We test whether the main results are sensitive to including capital gains by splitting the donor pool into one group of countries that include capital gains in their time series, and one group where capital gains are excluded (for a few countries, both type of series exist, then different series for that country goes in both groups). A new synthetic control group will be generated using these new smaller donor pools, with everything else held equal. Unfortunately we cannot do this for the U.K. because of lack of data, but for Japan the data availability is good and we access data for all top income shares both including and excluding realized capital gains.

Figures A8a and A8b shows that increased realized capital gains in the Japanese top income groups do not reinforce the link between financial deregulation and inequality. ${ }^{28}$ Including realized capital gains in Japanese and the synthetic control's top income shares removes the impact of the Big Bang and, if anything, top income shares even appear to decrease after the deregulation. In other words, the figure clearly shows that the documented positive effect on top income shares by the Japanese Big Bang was due to increases in incomes other than realized capital gains. This bolsters our previous conclusions about higher wages in the financial sector as a key mechanism for understanding the observed patterns.

\footnotetext{
${ }^{28}$ The countries included in the synthetic control group were Australia, Spain and the U.S.
} 
Table A12: Countries in the unified synthetic control group

\begin{tabular}{lrr}
\hline & Synthetic United Kingdom & Synthetic Japan \\
\hline \hline Australia & 0 & 0.0363 \\
Canada & 0.1320 & 0 \\
Denmark & 0 & 0 \\
France & 0 & 0.5824 \\
Germany & 0 & $\cdot$ \\
Italy & 0 & 0 \\
Japan & 0.0995 & $\cdot$ \\
Netherlands & 0.7578 & 0 \\
New Zealand & 0 & $\cdot$ \\
Norway & 0 & 0 \\
Spain & $\cdot$ & 0.3814 \\
Sweden & 0 & 0 \\
Switerland & 0.0107 & 0 \\
United States & $\cdot$ & 0 \\
\hline
\end{tabular}

Figure A8: The effect of realized Capital Gains for Japan

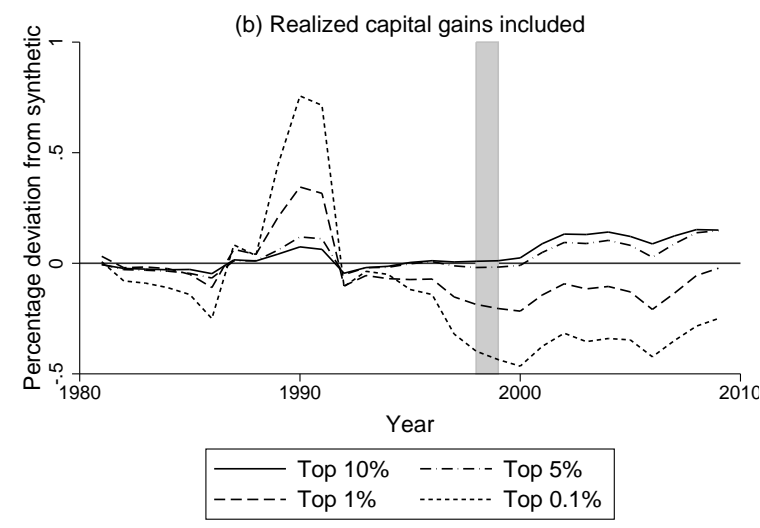

(a) Realized capital gains included

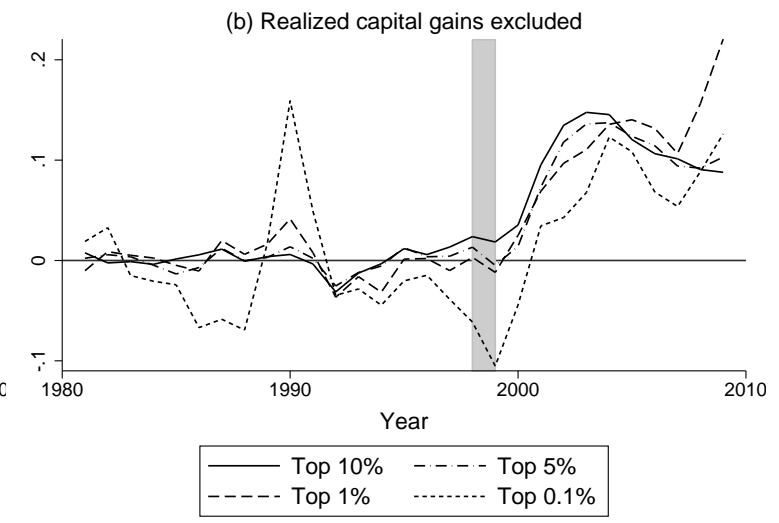

(b) Realized capital gains excluded

Note: Percentage deviations from the synthetic control group for each top income share. 


\section{Taxation of top incomes in the U.K. and Japan}

The taxation of top incomes has attracted much attention over the years, but still the degree of accuracy when it comes to measuring the actual marginal (and average) tax rates that top earners pay is often surprisingly low. Notably, many studies use the statutory top income tax rate as measure for the marginal tax rate that top income earners meet. However, this rate is rarely paid by everyone in the top income decile, but rather most often by quite exclusive groups in the very top of the distribution. Furthermore, the share of people paying this rate varies both over time and across countries due to differences and changes in income thresholds and tax laws.

We use in our study the top statutory rates as a proxy for top marginal income taxes, partly because it is correlated with overall taxation of top incomes and because it is available for many countries and long time periods. Still, we also recognize the occasionally bad coverage of the statutory rate and complement it with a measure of the marginal tax rate paid by income earners with income equal to five times GDP per capita calculated for Rydqvist, Spitzman and Strebulaev (2014). This is unfortunately not available for all countries in our sample.

In addition, we examine the tax rate paid by different top income groups in the U.K. and Japan specifically using other sources. For the U.K., we calculate these rates using information about average incomes in different top income groups available in the WID and tax schedules from the OECD tax Database. ${ }^{29}$.

Figure A9 shows this development over the period for the groups as reported in the WID: top 10-5 percent, top 5-1 percent, the top 1-0.5 percent and the top 1 percent. The figure shows that marginal tax rates dropped sharply for the very top groups in 1988, when the British government effectuated a tax cut. In 1990, the British tax system changed again, this time by moving from joint household taxation to individual taxation (see, e.g., Giles and Johnson, 1994; Atkinson, 2007).

Figure A10 shows the marginal tax rates paid by top wage earners in Japan over most of the studied period, using series reported by Moriguchi and Saez (2008), appendix C. ${ }^{30}$ It can be noted that while the top statutory rate dropped quite notably in 1999, from 47.5 percent to 35 percent (one fourth of the marginal rate), basically nothing happened with the marginal wage income tax paid but virtually all income earners. The figure shows that the rates were flat from the mid-1990s through the 2000s for wage incomes up to and including the 99.9th wage percentile.

\footnotetext{
${ }^{29}$ Specifically, we use data files for historical tax rates over the period 1981-1999 available on their website, and sheets labeled PART I. Taxation of Wage Income. Table I.1. Central government personal income tax rates and thresholds.

${ }^{30}$ We use data from Table C3: Wage Income Tax and Marginal Tax Rates in Japan, 1951-2005.
} 
Figure A9: Tax rates for top income earners, U.K.

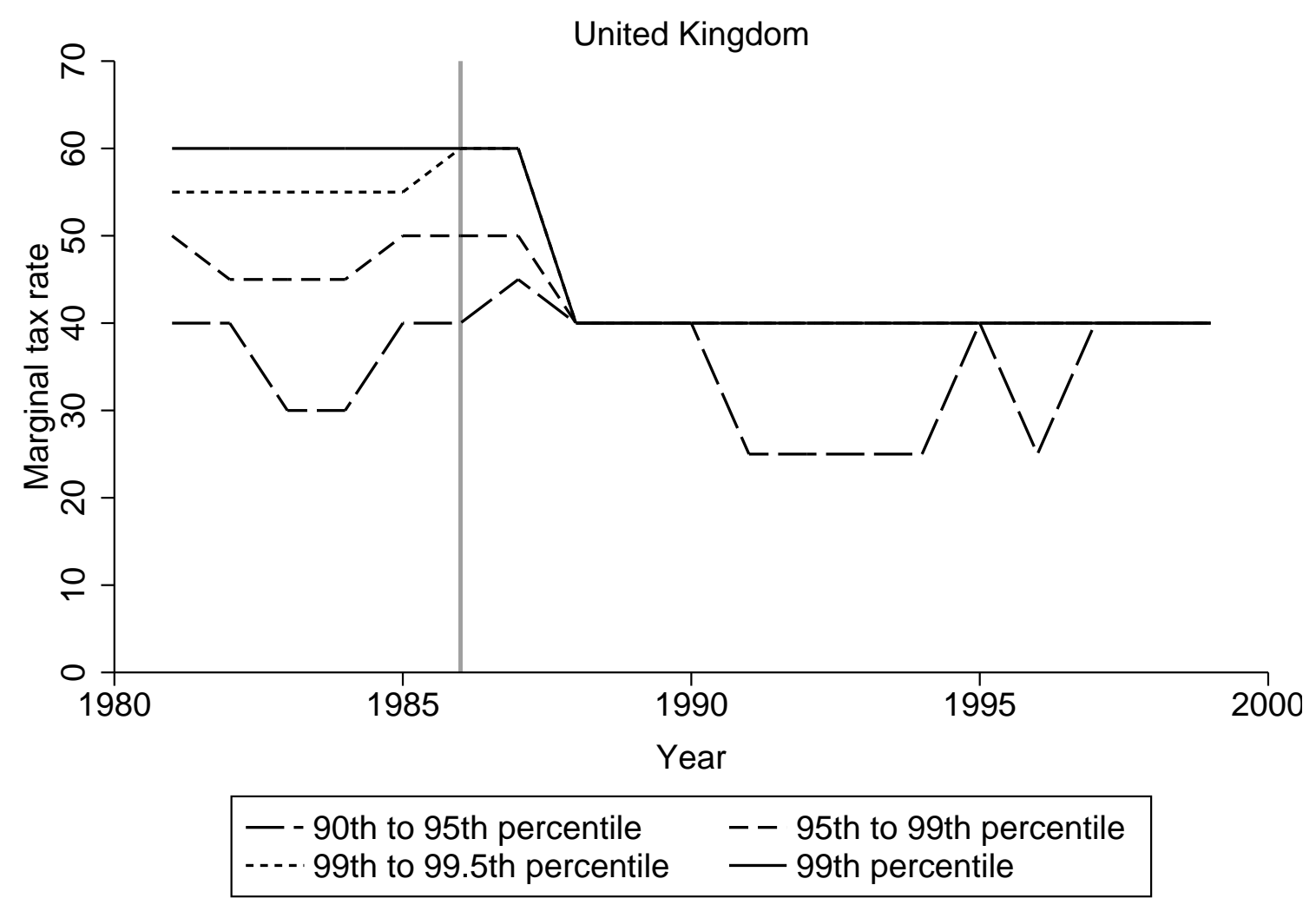


Figure A10: Tax rates for top income earners, Japan

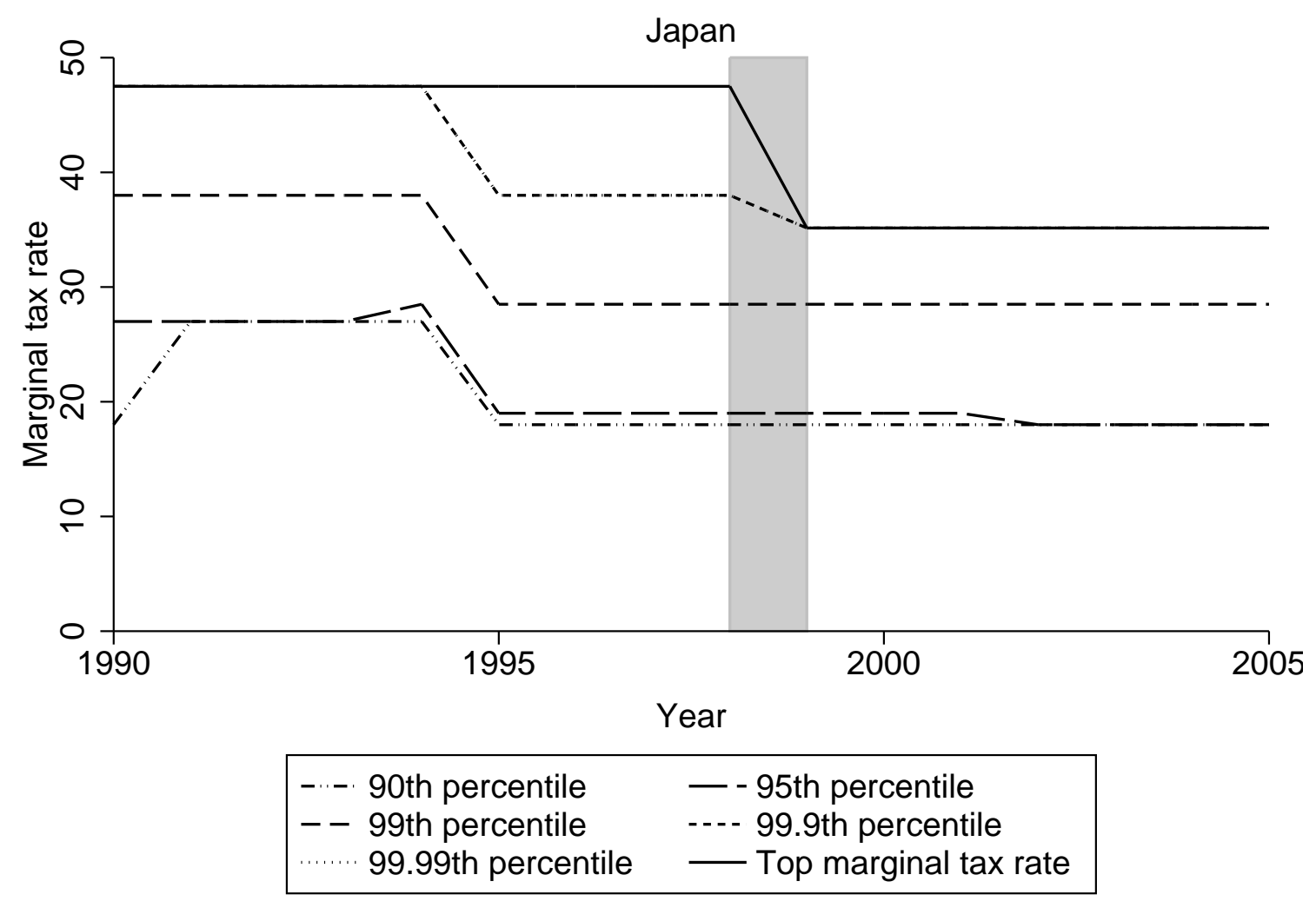




\section{Appendix references}

Bekaert, G., Harvey, C. R., and Lundblad, C. (2006). "Growth Volatility and Financial Liberalization." Journal of International Money and Finance 25(3): 370-403.

Chinn, M. D., and Ito, H. (2008). "A New Measure of Financial Openness." Journal of Comparative Policy Analysis 10(3): 309-322.

Comin, D. and Hobijin, B. (2009). The Chat Dataset. NBER Working paper 15139.

Giles, C. and Johnson, P. (1994). "Taxes Down, Taxes Up: The Effects of a Decade of Tax Changes." Institute for Fiscal Studies Commentary No. 41, London: Institute for Fiscal Studies.

Kaminsky, G., and Schmukler, S. (2008). "Short-Run Pain, Long-Run Gain: Financial Liberalization and Stock Market Cycles." Review of Finance 12(2): 253-292.

Rydqvist, K., Spizman, J., and Strebulaev, I. (2014). "Government Policy and Ownership of Equity Securities." Journal of Financial Economics 111(1): 70-85. 